\title{
Nonlinear Optimal-Based Vibration Control of a Wind Turbine Tower Using Hybrid vs. Magnetorheological Tuned Vibration Absorber
}

\author{
Paweł Martynowicz
}

Citation: Martynowicz, P. Nonlinear Optimal-Based Vibration Control of a Wind Turbine Tower Using Hybrid vs. Magnetorheological Tuned Vibration Absorber. Energies 2021, 14, 5145. https://doi.org/10.3390/ en14165145

Academic Editor:

Francesco Castellani

Received: 18 July 2021

Accepted: 17 August 2021

Published: 20 August 2021

Publisher's Note: MDPI stays neutral with regard to jurisdictional claims in published maps and institutional affiliations.

Copyright: (C) 2021 by the author. Licensee MDPI, Basel, Switzerland. This article is an open access article distributed under the terms and conditions of the Creative Commons Attribution (CC BY) license (https:// creativecommons.org/licenses/by/ $4.0 /)$.
Department of Process Control, AGH University of Science and Technology, Mickiewicza 30 Ave, 30-059 Kraków, Poland; pmartyn@agh.edu.pl

\begin{abstract}
This paper presents an implementation of a nonlinear optimal-based wind turbine tower vibration control method. An NREL 5.0 MW tower-nacelle model equipped with a hybrid tuned vibration absorber (HTVA) is analysed against the model equipped with a magnetorheological TVA (MRTVA). For control purposes, a $3 \mathrm{kN}$ active actuator in parallel with a passive TVA is used in the HTVA system, while an MR damper is built in the MRTVA instead of a viscous damper, as in a standard TVA. All actuator force constraints are embedded in the implemented nonlinear control techniques. By employing the Pontryagin maximum principle, the nonlinear optimal HTVA control proposition was derived along with its simplified revisions to avoid a high computational load during real-time control. The advantage of HTVA over MRTVA in vibration attenuation is evident within the first tower bending frequency neighbourhood, with HTVA also requiring less working space. Using the appropriate optimisation fields enabled an 8-fold reduction of HTVA energy demand along with a (further) $29 \%$ reduction of its working space while maintaining a significant advantage of HTVA over the passive TVA. The obtained results are encouraging for the assumed mass ratio and actuator force limitations, proving the effectiveness and validity of the proposed approaches.
\end{abstract}

Keywords: nonlinear optimal control; hybrid tuned vibration absorber; magnetorheological tuned vibration absorber; wind turbine tower vibration; NREL 5.0 MW

\section{Introduction}

Slender structures such as masts, chimneys [1], bridges [2,3], plates [4], high-rise buildings [5,6], beams [7], or wind turbines [8-10] are particularly vulnerable to vibrations and their consequences. Thus, most of them are equipped with vibration reduction and fatigue mitigation solutions.

Wind turbines experience time-varying external loads, including wind speed variations, wind shear (yielding differences in inflow conditions for the blades), Karman vortices, a blade passing effect, along with the unbalance or load fluctuations of the rotating machinery (and waves/ice load for offshore structures), all of them contributing to tower and blade structural vibration, fatigue, wear, or damage [11]. Previous research on wind turbine vibration [12,13], and in particular, tower vibration [14,15], shows that first and second tower bending modes (especially first lateral) are characterised with the lowest modal damping ratio. Moreover, the first tower bending mode has dominant modal mass participation (usually greater than 60\%) [14]. Thus, the problem of the wind turbine towers' first bending mode control [16-18] is addressed in the present paper as an illustrative example for control method implementation, using a simplified tower-nacelle model of the (onshore version) National Renewable Energy Laboratory's (NREL) 5.0 MW wind turbine structure [12,19]. The regarded model dynamics include disturbance load without modelling nature of the disturbing forces-the model does not focus on blades or drivetrain dynamics, tower-blade interactions, etc.; while their contribution to system oscillations is 
represented by a concentrated force applied to the nacelle-rotor assembly (that incorporates blades, a hub, shaft, generator, and a gearbox) fixed to the top of the tower [20,21].

The concepts utilised to mitigate vibration cover (dynamic) vibration absorbers, VAs, including tuned vibration absorbers, TVAs (otherwise called tuned mass dampers, TMDs) [22], tuned liquid dampers, tuned pendulum dampers, viscoelastic/hydraulic/ friction/granular dampers, bracing systems, piezoelectric actuators, etc. Among them, TVAs are the most frequently used vibration attenuation solutions. A passive TVA consists of an additional moving mass, a spring and a viscous damper, the parameters of which are tuned to the specific vibration mode of the structure [23]. Passive TVAs are effective in a narrow frequency range but cannot cope with a wider excitation spectrum [10]. In real-world conditions, the modal characteristics of many structures may vary in time due to external (e.g., temperature change, icing) or operational (e.g., mechanical wear, structure fatigue) factors [24], leading to the TVA detuning, which may be a severe problem if the structure's damping is low. Thus, more advanced (T)VA (i.e., VA or TVA) solutions are implemented to enhance passive TVA efficiency and applicability. Among them, semiactive, active, and hybrid (T)VAs are placed. Active (T)VA uses an active cylinder/actuator in place of both a viscous damper and a spring (or in place of a viscous damper alone) $[25,26]$. Active (T)VAs are characterised by high efficiency; however, their energy demand and robustness concerns are fundamental. The limitations of the passive and active TVAs yielded the introduction of semiactive and hybrid solutions [27].

Semiactive TVA employs a semiactive control device to tune the TVA to the current vibration profile; the control actuators do not add mechanical energy directly to the structure, as in active TVAs [28]. Frequently used semiactive actuators include magnetorheological (MR) [29-31] or electrorheological (ER) dampers, variable orifice dampers, or mini electric drives that use a small amount of energy to amend system properties [6,32]. Semiactive TVAs provide wider ranges of operational frequencies or/and increased efficiency for the frequency of tuning (in comparison with passive TVAs) [16,17], higher reliability, and significantly lower energy requirements than active systems $[3,28]$. Simulations and experiments show that implementing a semiactive actuator (e.g., an MR damper) in the TVA system may lead to significant vibration reduction with regard to passive TVA [33,34].

Hybrid TVA (HTVA) is a combination of a passive TVA with an active actuator (sometimes with an active TVA) [27]. HTVAs are among the most common and reliable devices employed in full-scale civil engineering structures $[35,36]$. The active force of HTVA increases both the vibration reduction efficiency of the TVA and its robustness to changes in the dynamic behaviour of the structure. Energy/power and force requirements of a standard HTVA actuator are much lower than those of an active (T)VA of comparable performance [28]. This promoted the widespread application of HTVA for structural control and grounded our interest in it.

Specific control solutions must be used as wind turbine structural behaviour, and actuator dynamics (including force output or stroke limitations, i.e. operating characteristics saturation) are intrinsically nonlinear. Most real-time vibration control techniques are based on a simple bang-bang approach [37], soft computing methods [1], or more advanced two-stage concepts with a calculation of an optimal actuator force (being the first stage) and precise actuator force tracking (being the second stage) $[3,18]$. Two-stage concepts are compromised by the accuracy of mapping the required (by the first stage) force pattern with the actuator used. The most frequent force tracking problems are actuator dynamics nonlinearities and time constants/delays. For semiactive elements (as MR dampers), the impossibility to generate active forces is also a major force mapping issue. Another problem with TVA implementation is the constrained actuator force output (resulting in a far-from-optimal or even detrimental control pattern) and the limited TVA working space. The latter often requires end-stop collision dampers or additional springs of increased stiffness [38] that effectively increase (up-tune) the TVA frequency at large strokes; this may further increase the primary structure deflection amplitude. Moreover, some advanced first stage algorithms need real-time (dominant) frequency determination, 
which may be an issue for random (e.g., seismic) or polyperiodic (due to wind, waves, and rotation) vibrations.

Recently the author proposed an entirely different vibration control concept for a structure/system equipped with MRTVA (i.e., magnetorheological TVA, consisting of a mass, a spring, and an MR damper in parallel) $[33,34]$, utilising nonlinear control techniques. Nonlinear control methods include Pontryagin maximum principle-based methods [7,39], control Lyapunov function-based methods [2,5,40], linearisation methods with linear optimal control theory (LQR/LQG/H2/Ho) based on the Riccati equation/approximating sequence of the Riccati equations [41,42], etc. Along with the advantages, each method group has its disadvantages, throughout which the most common is the high computational load necessary for the real-time implementation and control authority degradation in the presence of disturbances or unmodelled dynamics.

The above issues are addressed within the scope of the current paper, utilising maximum principle-based nonlinear optimal control as the derivation foundation. An NREL 5.0 MW tower-nacelle model (representing the first tower bending mode) with HTVA is considered a research platform for this tower vibration reduction problem. The analysed configuration may be regarded as an HTVA installed in the nacelle (in a side-side direction of operation) to address the tower's first lateral bending mode of the lowest modal damping ratio. The HTVA actuator force nonlinearities are embedded in the proposed control method, eliminating possible efficiency and robustness issues associated with a calculated optimal or optimal-based control function inaccurately mapped or beyond the permissible actuator range. The produced control is a direct input signal (i.e., voltage) of the assumed exemplary actuator.

This paper is organised as follows. In the following section, the regarded model is introduced. Subsequently, the optimal control problem formulation and solution are given. Then, implementation techniques, including optimal-based control and hybrid ground-hook control, are derived. Test configurations are described afterwards. The paper is summarised with control results, remarks, and conclusions.

\section{NREL 5.0 MW Tower-Nacelle Model with HTVA}

The tower-nacelle model of the NREL 5.0 MW wind turbine structure [12,19] is considered a primary vibrating system. The control analysis focuses on the 1st bending mode of the tower-the associated modal parameters are mass $m_{1}$, stiffness $k_{1}$, and damping $c_{1}$ (Figure 1). An HTVA of mass $m_{2}$, stiffness $k_{2}$, damping $c_{2}$, and active force $F_{a}$ of maximum absolute value $F_{\text {sat }}$ is built at the top of a tower/in the nacelle (where the maximum deflection of the regarded mode occurs) to address the tower's 1st bending mode attenuation effectively. The movements of both $m_{1}$ and $m_{2}$ are restricted to being linear displacement $x_{1}$ and $x_{2}$ (respectively) along the horizontal axis, which is also the axis of an excitation force $F_{e}$ applied to the nacelle/rotor (assuming small tower deflection angles). Based on the previous research, the mass $m_{2}$ is assumed to be 10 tons $\left(2.33 \%\right.$ of $\left.m_{1}\right)$ to optimise performance vs. the added mass ratio $[16,19,34,43,44]$. The stiffness $\left(k_{2}\right)$ and damping $\left(c_{2}\right)$ parameters were calculated according to Den Hartog [23]. The values of the regarded system parameters are presented in Table 1, while the system diagram is depicted in Figure 1. 


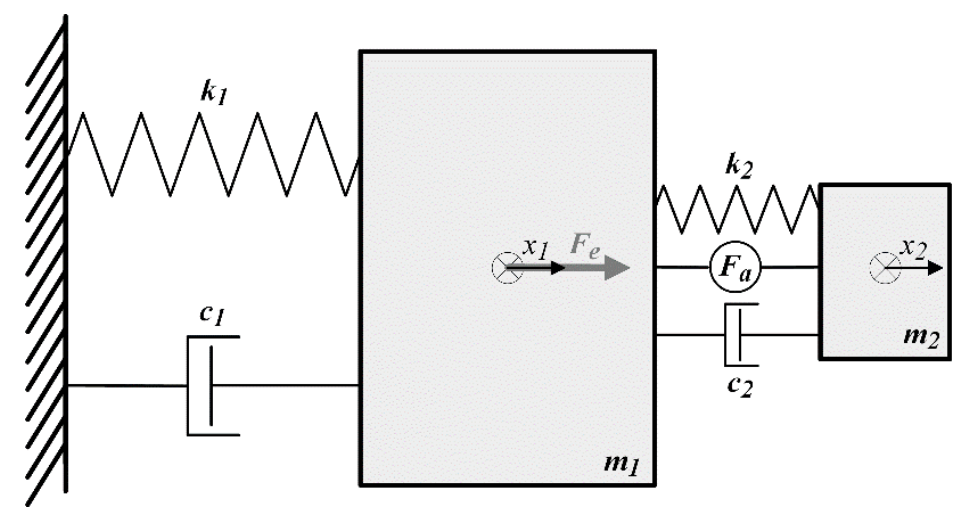

Figure 1. Two-body diagram of a regarded system with hybrid tuned vibration absorber (HTVA).

Table 1. NREL 5.0 MW with HTVA model parameters.

\begin{tabular}{cc}
\hline Parameter & Value \\
\hline $\mathrm{m}_{1}$ & $428.790 \mathrm{Mg}$ \\
\hline $\mathrm{k}_{1}$ & $1545.6 \mathrm{kN} / \mathrm{m}$ \\
\hline $\mathrm{c}_{1}$ & $3.5420 \mathrm{kNs} / \mathrm{m}$ \\
\hline $\mathrm{m}_{2}$ & $10 \mathrm{Mg}$ \\
\hline $\mathrm{k}_{2}$ & $34.421 \mathrm{kN} / \mathrm{m}$ \\
\hline $\mathrm{c}_{2}$ & $3.3521 \mathrm{kNs} / \mathrm{m}$ \\
\hline $\mathrm{F}_{\mathrm{m}}$ & $3.0 \mathrm{kN}$ \\
\hline $\mathrm{a}_{1}, \mathrm{a}_{2}, \mathrm{a}$ & $1.50 \mathrm{~V}, 4.101 / \mathrm{V}, 6.15$ \\
\hline $\mathrm{F}_{\mathrm{sat}}$ & $F_{m} \operatorname{tgh}(a) \cong 3.0 \mathrm{kN}$ \\
\hline
\end{tabular}

\section{Optimal Control Problem Formulation and Solution}

Consider the equation of a vibrating system with an HTVA:

$$
\dot{z}(t)=f(z(t), u(t), t), \ldots t \in\left[t_{0}, t_{1}\right],
$$

where $z(t)$ is a state vector:

$$
z(t)=\left[\begin{array}{llll}
z_{1}(t) & z_{2}(t) & z_{3}(t) & z_{4}(t)
\end{array}\right]^{T}
$$

with the initial condition:

$$
z\left(t_{0}\right)=z_{0}
$$

$u(t)$ is a piecewise-continuous, scalar control function $(u(t) \in U)$, and the quality index to be minimised is:

$$
G(z, u)=\int_{t_{0}}^{t_{1}} g(z(t), u(t), t) d t
$$

Following Section 2, assume: $z_{1}=x_{1}, z_{2}=\dot{x}_{1}, z_{3}=x_{2}, z_{4}=\dot{x}_{2}$, thus:

$$
f(z(t), u(t), t)=\left[\begin{array}{c}
z_{2}(t) \\
\frac{1}{m_{1}}\left(-\left(k_{1}+k_{2}\right) z_{1}(t)-\left(c_{1}+c_{2}\right) z_{2}(t)+k_{2} z_{3}(t)+c_{2} z_{4}(t)-F_{a}(t)+F_{e}(t)\right) \\
z_{4}(t) \\
\frac{1}{m_{2}}\left(k_{2} z_{1}(t)+c_{2} z_{2}(t)-k_{2} z_{3}(t)-c_{2} z_{4}(t)+F_{a}(t)\right)
\end{array}\right]
$$

where $F_{e}(t)$ is the excitation force applied to the primary structure. To account for the actuator operating characteristics' nonlinearity (Figure 2), as in [45] (with negative forces incorporated to obtain the profile symmetrical with respect to the origin), including its 
output force $F_{a}$ constraints, i.e., saturation to $\left[-F_{\text {sat }}, F_{\text {sat }}\right]$ range $\left(F_{\text {sat }}>0\right.$, see Table 1$)$, it was further assumed:

- $\quad$ an actuator input voltage $v(t)=a_{1} \sin u(t)$ constrained to $\left[-a_{1}, a_{1}\right] \mathrm{V}$ range,

- $\quad$ an unconstrained control signal $u(t) \in U, U=(-\infty, \infty)$,

- $\quad$ an actuator force $F_{a}(v(t))=F_{m} \operatorname{tgh}\left(a_{2} v(t)\right)$; thus: $F_{a}(u(t))=F_{m} \operatorname{tgh}(\operatorname{a} \sin u(t))$ (see Table $1, a=a_{1} a_{2}$; note that $\operatorname{tgh}(a) \cong 1$ with roundoff error below $\left.10^{-5}\right)$.

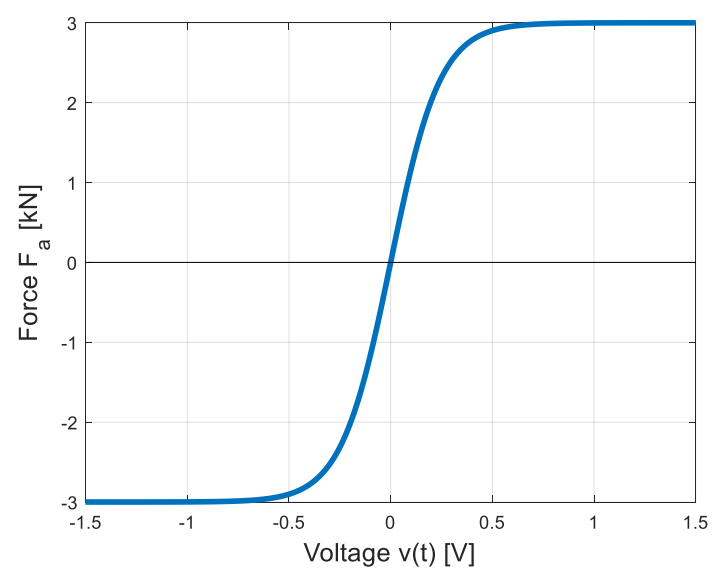

Figure 2. Actuator force nonlinearity.

The actuator time constants were assumed negligible for the current analysis stage (time constant associated with the regarded NREL 5.0 MW first tower bending mode is above $3 \mathrm{~s})$.

The considered quality index is:

$$
\begin{array}{cc}
g(z(t), u(t), t)=\quad & g_{11} z_{1} 2(t)+g_{12} z_{2} 2(t)+g_{13}\left(z_{1}(t)-z_{3}(t)\right)^{2} \\
+g_{14}\left(z_{2}(t)-z_{4}(t)\right)^{2}+g_{22} F_{a} 2(u(t))+g_{23} P_{a} 2(z(t), u(t), t)
\end{array}
$$

to account for the minimisation of the primary structure displacement $z_{1}$ and velocity $z_{2}$, the HTVA stroke $z_{1}-z_{3}$ and relative velocity $z_{2}-z_{4}$, and the actuator control force $F_{a}$ and power $P_{a}$, where: $P_{a}(z(t), u(t), t)=F_{a}(u(t))\left(z_{2}(t)-z_{4}(t)\right)$.

Assume a Hamiltonian function in the form:

$$
H(\xi(t), z(t), u(t), t)=-g(z(t), u(t), t)+\xi^{T}(t) f(z(t), u(t), t)
$$

If $(z *(t), u *(t))$ is an optimal controlled process, there exists an adjoint (co-state) vector function $\xi$ satisfying the equation:

$$
\dot{\xi}(t)=-f_{z}^{* T}\left(z^{*}(t), u^{*}(t), t\right) \xi(t)+g_{z}^{T}\left(z^{*}(t), u^{*}(t), t\right), \quad t \in\left[t_{0}, t_{1}\right]
$$

with a terminal (transversality) condition:

$$
\xi\left(t_{1}\right)=0
$$

so that $u^{*}(t)$ maximises the Hamiltonian over the set $U$ for almost all $t \in\left[t_{0}, t_{1}\right]$ (Pontryagin maximum principle) [46]. The functions $f$ and $g$ are assumed to be continuously differentiable with respect to the state and continuous with respect to time and control, while $f_{z}$ and $g_{z}$ are $f$ and $g$ derivatives with respect to $z$.

For the regarded system, the co-state vector is:

$$
\xi(t)=\left[\begin{array}{llll}
\xi_{1}(t) & \xi_{2}(t) & \xi_{3}(t) & \xi_{4}(t)
\end{array}\right]^{T}
$$


while:

$$
f_{z}^{* T}\left(z^{*}(t), u^{*}(t), t\right)=\left[\begin{array}{cccc}
0 & -\frac{1}{m_{1}}\left(k_{1}+k_{2}\right) & 0 & \frac{1}{m_{2}} k_{2} \\
1 & -\frac{1}{m_{1}}\left(c_{1}+c_{2}\right) & 0 & \frac{1}{m_{2}} c_{2} \\
0 & \frac{1}{m_{1}} k_{2} & 0 & -\frac{1}{m_{2}} k_{2} \\
0 & \frac{1}{m_{1}} c_{2} & 1 & -\frac{1}{m_{2}} c_{2}
\end{array}\right]
$$

and:

$$
g_{z}^{T}\left(z^{*}(t), u^{*}(t), t\right)=\left[\begin{array}{c}
2 g_{11} z_{1}^{*}(t)+2 g_{13}\left(z_{1}^{*}(t)-z_{3}^{*}(t)\right) \\
2 g_{12} z_{2}^{*}(t)+2 g_{23} F_{a}^{2}\left(u^{*}(t)\right)\left(z_{2}^{*}(t)-z_{4}^{*}(t)\right)+2 g_{14}\left(z_{2}^{*}(t)-z_{4}^{*}(t)\right) \\
-2 g_{13}\left(z_{1}^{*}(t)-z_{3}^{*}(t)\right) \\
-2 g_{23} F_{a}^{2}\left(u^{*}(t)\right)\left(z_{2}^{*}(t)-z_{4}^{*}(t)\right)-2 g_{14}\left(z_{2}^{*}(t)-z_{4}^{*}(t)\right)
\end{array}\right]
$$

The Hamiltonian maximisation condition is [46]:

\section{$\frac{\partial H\left(\xi(t), z^{*}(t), u(t), t\right)}{\partial u(t)}=$}

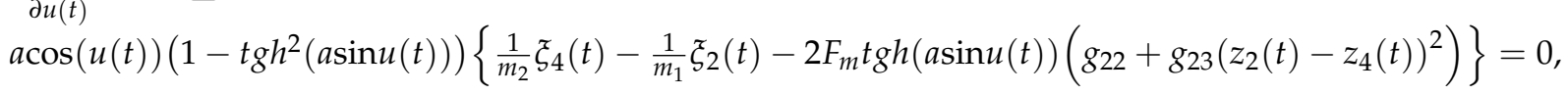

or (assuming $g_{22} \neq 0$; note that $a\left(1-\operatorname{tgh}^{2}(a \sin u(t))\right)>0$ for all $\left.u(t) \in U\right)$ :

$$
\cos (u(t))\left\{\frac{1}{2 F_{m}\left[g_{22}+g_{23}\left(z_{2}(t)-z_{4}(t)\right)^{2}\right]}\left(\frac{1}{m_{2}} \xi_{4}(t)-\frac{1}{m_{1}} \xi_{2}(t)\right)-\operatorname{tgh}(\operatorname{asin} u(t))\right\}=0
$$

with the appropriate sign change regime, as analysed hereinafter; for attention, consider $u(t)$ range of $[-\pi / 2, \pi / 2]$ (see Figure 3 , including zoom of point $(-\pi / 2,1)$ neighbourhood in its top left corner).

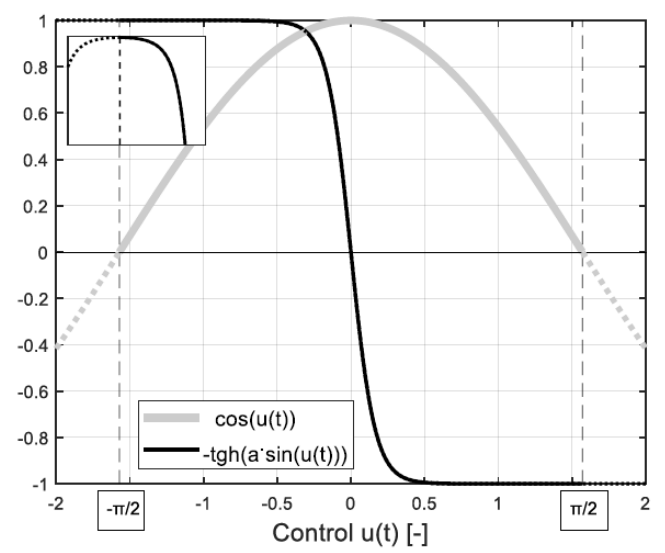

Figure 3. Hamiltonian derivative sign analysis.

Equation (14) yields proposition (15a)-(15c) covering three disjoint and complementary cases (see Figure 3):

1. if $\left\{\frac{1}{2 F_{m}\left[g_{22}+g_{23}\left(z_{2}(t)-z_{4}(t)\right)^{2}\right]}\left(\frac{1}{m_{2}} \xi_{4}(t)-\frac{1}{m_{1}} \xi_{2}(t)\right)\right\} \leq-\operatorname{tgh}(a)$, then (14) is fulfilled and $\frac{\partial H\left(\xi(t), z^{*}(t), u(t), t\right)}{\partial u(t)}$ exhibits $+/-$ sign change (Hamiltonian maximisation) for: $u^{*}(t)=$ $-\frac{\pi}{2}$ only, so:

$$
v^{*}(t)=-a_{1}, F_{a}^{*}\left(u^{*}(t)\right)=-F_{m} \operatorname{tgh}(a)=-F_{\text {sat }}
$$


2. if $\left\{\frac{1}{2 F_{m}\left[g_{22}+g_{23}\left(z_{2}(t)-z_{4}(t)\right)^{2}\right]}\left(\frac{1}{m_{2}} \xi_{4}(t)-\frac{1}{m_{1}} \xi_{2}(t)\right)\right\} \geq \operatorname{tgh}(a)$, then (14) is fulfilled and $\frac{\partial H\left(\xi(t), z^{*}(t), u(t), t\right)}{\partial u(t)}$ exhibits $+/-$ sign change for: $u^{*}(t)=\frac{\pi}{2}$ only, so:

$$
v^{*}(t)=a_{1}, F_{a}^{*}\left(u^{*}(t)\right)=F_{m} \operatorname{tgh}(a)=F_{\text {sat }},
$$

3. if $\left\{\frac{1}{2 F_{m}\left[g_{22}+g_{23}\left(z_{2}(t)-z_{4}(t)\right)^{2}\right]}\left(\frac{1}{m_{2}} \xi_{4}(t)-\frac{1}{m_{1}} \xi_{2}(t)\right)\right\} \in(-\operatorname{tgh}(a), \operatorname{tgh}(a))$, then (14) is fulfilled and $\frac{\partial H\left(\tilde{\xi}(t), z^{*}(t), u(t), t\right)}{\partial u(t)}$ exhibits $+/-$ sign change for: $\operatorname{tgh}\left(a \sin u^{*}(t)\right)=\frac{1}{2 F_{m}\left[g_{22}+g_{23}\left(z_{2}(t)-z_{4}(t)\right)^{2}\right]}\left(\frac{1}{m_{2}} \xi_{4}(t)-\frac{1}{m_{1}} \xi_{2}(t)\right)$ only, so:

$$
\begin{aligned}
& v^{*}(t)=\frac{1}{a_{2}} \operatorname{arctgh}\left\{\frac{1}{2 F_{m}\left[g_{22}+g_{23}\left(z_{2}^{*}(t)-z_{4}^{*}(t)\right)^{2}\right]}\left(\frac{1}{m_{2}} \xi_{4}(t)-\frac{1}{m_{1}} \xi_{2}(t)\right)\right\}, \\
& F_{a}^{*}\left(u^{*}(t)\right)=\frac{1}{2\left[g_{22}+g_{23}\left(z_{2}^{*}(t)-z_{4}^{*}(t)\right)^{2}\right]}\left(\frac{1}{m_{2}} \xi_{4}(t)-\frac{1}{m_{1}} \xi_{2}(t)\right)
\end{aligned}
$$

The obtained solution is consistent with $[33,47]$.

\section{Implementation Techniques}

The common implementation technique of the optimal control for nonlinear systems is an offline computation of the $u^{*}(t)$ pattern using the two-point boundary value problem $(B V P)(1)(3)(8)(9)$ solution. Nonetheless, (so determined) open-loop control does not provide robustness to uncertainties such as unmodeled dynamics and perturbations of external forces or initial conditions. Thus, perturbation control techniques are often employed $[39,48]$. However, proper linearisation may be a problem for many nonlinear systems with implicit relations, actuator saturation, etc. Here, the author proposes another approach.

\subsection{Optimal-Based Control}

To address the above issues regarding uncertain systems with nonlinearities, the $B V P(1)(3)(8)(9)$ may be solved at each sampling step $\left(t_{s}\right)$ of the real-time implementation. Recently, numerical and experimental implementation of such a nonlinear optimal control technique for a system with an MRTVA (see Section 5.2) was realised with the MATLAB/Simulink s-function and the brp $4 c$ two-point $B V P$ solving algorithm employed at every sampling step $[33,49]$. It was also shown that the BVP iteration procedure implicating large computational load might be omitted while maintaining robustness to external disturbances and unmodelled dynamics $[33,34]$ by utilising a short time horizon of, one after the other, optimal problem task with appropriate resetting time (i.e., terminal time $t_{1}$ ) of co-state integrators. As was previously proven [33], it may be demonstrated for the current study (see the following Remark 1 ) that the influence of the transversality condition (9) error is negligible. Thus, the optimal-based vibration control of the structure/system with HTVA, with all of its advantages (as method-embedded nonlinearities and various optimisation fields covered by the quality index), may be implemented in real-time using a simple data acquisition and control environment. In the present analysis, the baseline optimisation horizon of ten sampling steps is assumed. This approach is further designated simply by HTVA.

Remark 1. Some crucial steps of the transversality condition error analysis are given below (the detailed analysis-for the MRTVA application-is presented in [33]). 
Let $\tau$ be an arbitrary continuity point of the optimal control $u^{*}(t)$, and a needle-like variation of $u^{*}(t)$ is defined as:

$$
u^{\lambda}(t)=\left\{\begin{array}{cc}
u^{*}(t), & \text { if } t \notin[\tau-\lambda, \tau) \\
\mu, & \text { if } t \in[\tau-\lambda, \tau)
\end{array}\right.
$$

for $\mu$ being an arbitrary, fixed element of the set $U$, and sufficiently small $\lambda$. From [46]:

$$
y(\tau)=f\left(z^{*}(\tau), \mu, \tau\right)-f\left(z^{*}(\tau), u^{*}(\tau), \tau\right) .
$$

For any $t \in\left[\tau, t_{1}\right]$ :

$$
y(t)=y(\tau)+\int_{\tau}^{t} f_{z}\left(z^{*}(\theta), u^{*}(\theta), \theta\right) y(\theta) d \theta .
$$

Thus, the function $y(t)$ is the solution of:

$$
\dot{y}(t)=f_{z}\left(z^{*}(t), u^{*}(t), t\right) y(t),
$$

on $\left[\tau, t_{1}\right]$ with the initial condition (17). Hence:

$$
\xi^{T}(t) y(t)=-\int_{t}^{t_{1}} g_{z}\left(z^{*}(\theta), u^{*}(\theta), \theta\right) y(\theta) d \theta+\xi^{T}\left(t_{1}\right) y\left(t_{1}\right) .
$$

Here, in the elementary proof of the maximum principle [46] it is assumed: $\xi\left(t_{1}\right)=0$ according to (9). If $\xi\left(t_{1}\right) \neq 0$, thus for $t=\tau$ (17):

$$
\xi^{T}(\tau)\left[f\left(z^{*}(\tau), u^{*}(\tau), \tau\right)-f\left(z^{*}(\tau), \mu, \tau\right)\right]=\int_{\tau}^{t_{1}} g_{z}\left(z^{*}(\theta), u^{*}(\theta), \theta\right) y(\theta) d \theta-\xi^{T}\left(t_{1}\right) y\left(t_{1}\right) .
$$

For $\left(z^{*}(t), u^{*}(t)\right)$ being an optimal control process:

$$
g\left(z^{*}(\tau), \mu, \tau\right)-g\left(z^{*}(\tau), u^{*}(\tau), \tau\right) \geq-\int_{\tau}^{t_{1}} g_{z}\left(z^{*}(\theta), u^{*}(\theta), \theta\right) y(\theta) d \theta .
$$

Using (21) we get:

$$
\begin{gathered}
-g\left(z^{*}(\tau), u^{*}(\tau), \tau\right)+\xi^{T}(\tau) f\left(z^{*}(\tau), u^{*}(\tau), \tau\right) \geq-g\left(z^{*}(\tau), \mu, \tau\right)+\xi^{T}(\tau) f\left(z^{*}(\tau), \mu, \tau\right)- \\
-\xi^{T}\left(t_{1}\right) y\left(t_{1}\right),
\end{gathered}
$$

This can be written in the equivalent form:

$$
H\left(\xi(\tau), z^{*}(\tau), u^{*}(\tau), \tau\right) \geq H\left(\xi(\tau), z^{*}(\tau), \mu, \tau\right)-\xi^{T}\left(t_{1}\right) y\left(t_{1}\right) .
$$

For $\xi\left(t_{1}\right)=0$, the maximum principle is easily proved. For $\xi\left(t_{1}\right) \neq 0$, however, the product: $\xi^{T}\left(t_{1}\right) y\left(t_{1}\right)$ in (24) is estimated by calculating $y\left(t_{1}\right)$ with the use of equations (17) and (19). It was assumed: $y(\tau)=-f\left(z^{*}(\tau), u^{*}(\tau), \tau\right)$, which is of the order of magnitude equal or higher than: $f\left(z^{*}(\tau), \mu, \tau\right)-f\left(z^{*}(\tau), u^{*}(\tau), \tau\right)$, being the right-hand-side (RHS) of (17), concerning the values of the terms present in RHS of (5) for the regarded system parameters (Table 1$)$ and value ranges of $F_{e}(t), F_{a}(u(t))$ and excitation frequencies. Note that $f\left(z^{*}(\tau), \mu, \tau\right)$ is of the order of $f\left(z^{*}(\tau), u^{*}(\tau), \tau\right)$ as $\mu \in U$ in (16). Based on (24), the transversality condition (9) error $\varepsilon(\tau)$ is calculated as follows (considering $\left.H\left(\xi(\tau), z^{*}(\tau), u^{*}(\tau), \tau\right) \neq 0\right):$

$$
\frac{H\left(\xi(\tau), z^{*}(\tau), \mu, \tau\right)}{H\left(\xi(\tau), z^{*}(\tau), u^{*}(\tau), \tau\right)} \leq 1+\varepsilon(\tau)
$$




$$
\varepsilon(\tau)=\frac{\xi^{T}\left(t_{1}\right) y\left(t_{1}\right)}{H\left(\xi(\tau), z^{*}(\tau), u^{*}(\tau), \tau\right)} .
$$

The values of the quotient $\varepsilon(\tau)(26)$ are negligible for most of the time instants, except those corresponding to the protected structure deflection (nacelle-assembly displacement) $x_{1}$ sign change neighbourhood; thus, Hamiltonian is close to zero. Therefore, the control results are considered credible in all but a minor amount of time samples. The exemplary $\varepsilon(\tau)$ patterns for excitation frequencies of $0.27 \mathrm{~Hz}$ and $0.30 \mathrm{~Hz}$, and $t_{1}=10 t_{s}$, are presented in Figure 4. The value of $\tau=t_{s}=10^{-4} \mathrm{~s}$ was assumed; $\varepsilon(\tau)$ time patterns for different $\tau$ values are equivalent.

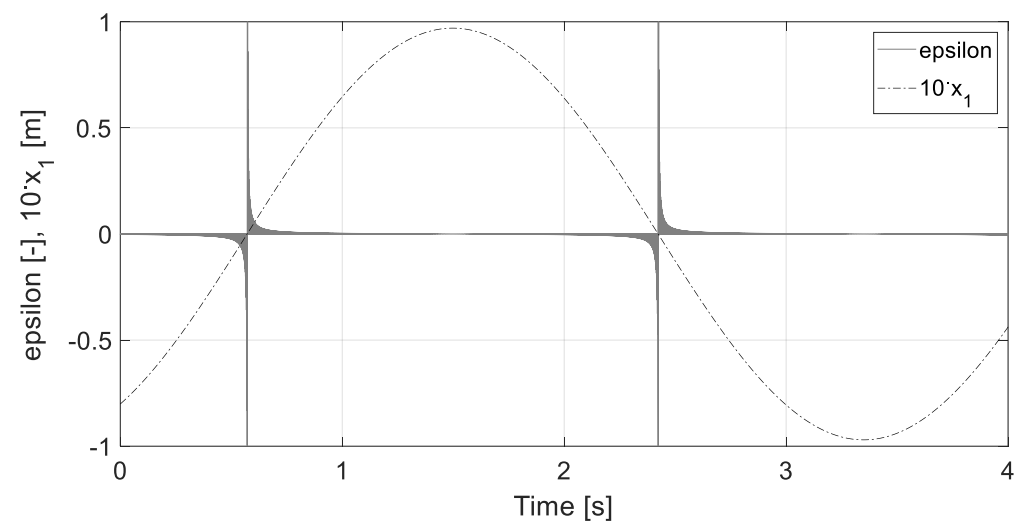

(a)

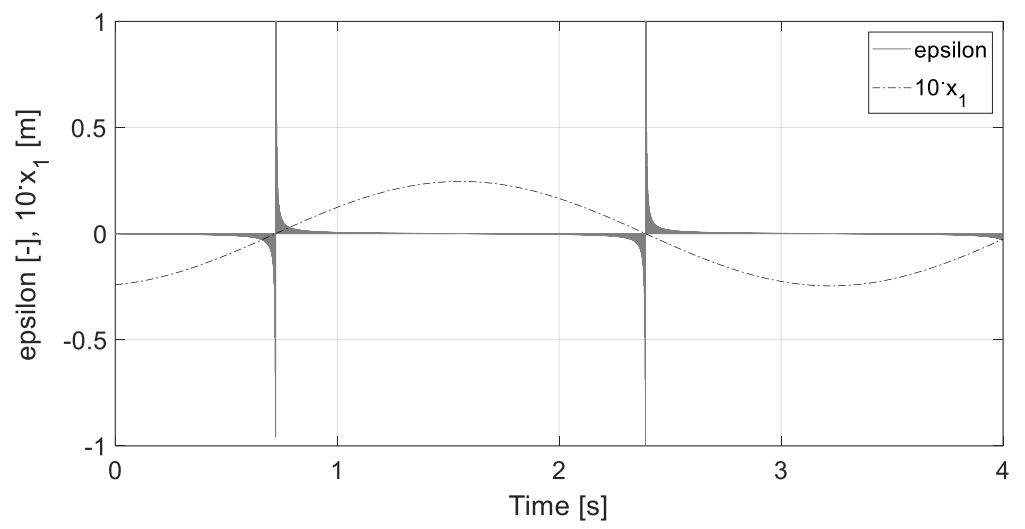

(b)

Figure 4. Assessed error $\varepsilon(\tau)$ time patterns at: (a) $0.27 \mathrm{~Hz}$, (b) $0.30 \mathrm{~Hz}$.

\subsection{Hybrid Ground-Hook Control}

On the basis of the proposition (15a)-(15c), the ground hook law for the HTVA is derived. For nonzero (positive) $g_{22}$ and $F_{m}$ values, a sign of the term: $\left\{\frac{1}{2 F_{m}\left[g_{22}+g_{23}\left(z_{2}(t)-z_{4}(t)\right)^{2}\right]}\left(\frac{1}{m_{2}} \xi_{4}(t)-\frac{1}{m_{1}} \xi_{2}(t)\right)\right\}$ (being the (15a)-(15c) antecedent left-handside, LHS) is consistent with the sign of the term: $-\xi_{2}(t)$, as: $\frac{1}{m_{1}} \xi_{2}(t)$ is many orders of magnitude greater than: $\frac{1}{m_{2}} \xi_{4}(t)$ for dominant $g_{11}$ value in the quality index (4) (i.e., when the primary structure/system displacement amplitude minimisation is a dominant objective). Moreover, the co-state dynamics' (8) first and second equation RHS s yield: $\operatorname{sgn}\left(-\xi_{2}(t)\right) \approx \operatorname{sgn}\left(x_{1}(t)\right)$, thus:

$$
\operatorname{sgn}\left\{\frac{1}{2 F_{m}\left[g_{22}+g_{23}\left(z_{2}(t)-z_{4}(t)\right)^{2}\right]}\left(\frac{1}{m_{2}} \xi_{4}(t)-\frac{1}{m_{1}} \xi_{2}(t)\right)\right\} \approx \operatorname{sgn}\left(x_{1}(t)\right) .
$$


The simulations prove that Formula (27) gives an adequately precise approximation of the proposition (15a)-(15c) antecedent LHS sign.

For adequately high $g_{11}$, it holds:

$$
\left|\frac{1}{2 F_{m}\left[g_{22}+g_{23}\left(z_{2}(t)-z_{4}(t)\right)^{2}\right]}\left(\frac{1}{m_{2}} \xi_{4}(t)-\frac{1}{m_{1}} \xi_{2}(t)\right)\right| \geq \operatorname{tgh}(a),
$$

for almost all time samples (see control $F_{a}$ time patterns of values being equal to $\mp F_{\text {sat }}$ for $g_{11}=10^{18}$, Section 6), effectively eliminating case 3 (15c) from the control proposition (15a)-(15c).

Thus, on the basis of (27) and (28), when the primary structure/system displacement amplitude minimisation is a sole objective, the HTVA optimal control proposition (15a)-(15c) simplifies to:

$$
v(t)=a_{1} \operatorname{sgn}\left(x_{1}(t)\right), F_{a}(t)=F_{\text {sat }} \operatorname{sgn}\left(x_{1}(t)\right),
$$

which is a two-level optimal-based displacement ground-hook law [37] (designated further by HTVA-GH), similar to the one derived by the author earlier for the MRTVA [33].

\section{Test Configurations}

The utilisation of the optimal-based HTVA is combined with the optimal-based MRTVA and a passive TVA tuned according to [23], hereinafter designated by passive TVA.

\subsection{Optimal-Based Control for the Wind Turbine Tower-Nacelle Model with HTVA}

For the purpose of the real-time control of the wind turbine (NREL 5.0 MW) tower first bending mode, the HTVA implementation techniques described in Sections $2-4$ are adopted: the optimal-based HTVA control is analysed along with the HTVA-GH law. The system parameters as in Table 1 are used along with the control force proposition (15a)-(15c).

\subsection{Optimal-Based Control for the Wind Turbine Tower-Nacelle Model with MRTVA}

The optimal-based MRTVA is implemented based on [34] (Figure 5), where the MR damper force $F_{m r}$ is given by:

$$
\begin{aligned}
& F_{m r}\left(z(t), i_{m r}(t), t\right)=\left(C_{1} i_{m r}(t)+C_{2}\right) \tanh \left\{v\left[\left(z_{4}(t)-z_{2}(t)\right)+\left(z_{3}(t)-z_{1}(t)\right)\right]\right\} \\
& +\left(C_{3} i_{m r}(t)+C_{4}\right)\left[\left(z_{4}(t)-z_{2}(t)\right)+\left(z_{3}(t)-z_{1}(t)\right)\right],
\end{aligned}
$$

according to the hyperbolic tangent model-an upscaled version of the MR damper as in $[33,34,50]$, while $i_{m r}(t)$ is the MR damper coil current obtained based on nonlinear optimal control problem formulation and solution (its construct is given by proposition (18) in [34] and omitted here for clarity), respecting the MR damper dynamics, resistance force constraints, and input current limitation to $\left[0, i_{\max }\right]$ range $[33,34]$. The value of $i_{\max }=1.0$ [A] was adopted. For the MRTVA implementation, the considered quality function is based on [34]:

$$
\begin{aligned}
g\left(z(t), i_{m r}(t), t\right)= & g_{11} z_{1} 2(t)+g_{12} z_{2} 2(t)+g_{13}\left(z_{1}(t)-z_{3}(t)\right)^{2}+g_{14}\left(z_{2}(t)-z_{4}(t)\right)^{2} \\
& +g_{21} i_{m r} 2(t)+g_{22} F_{m r} 2\left(z(t), i_{m r}(t), t\right),
\end{aligned}
$$

to minimise the primary structure deflection $z_{1}$ and velocity $z_{2}$, the MR damper stroke $\mathrm{z}_{1}-\mathrm{z}_{3}$ and piston velocity $z_{2}-z_{4}$, and the MR damper control current $i_{m r}$ and force $F_{m r}$. For the current study, the quality index (31) weights were set to minimise the primary structure deflection as a sole objective, or along with the MR damper force minimisation. For the purpose of the MR damper implementation instead of a viscous one (as for HTVA, see Figure 1 and Table 1), TVA spring stiffness was re-tuned to the $k_{2 M R}$ value (see Figure 5 and Table 2), as the MR damper resistance force also contains a stiffness component. The 
assumed MR damper model (30) parameters are given in Table 2. The above-described solution is further designated by MRTVA.

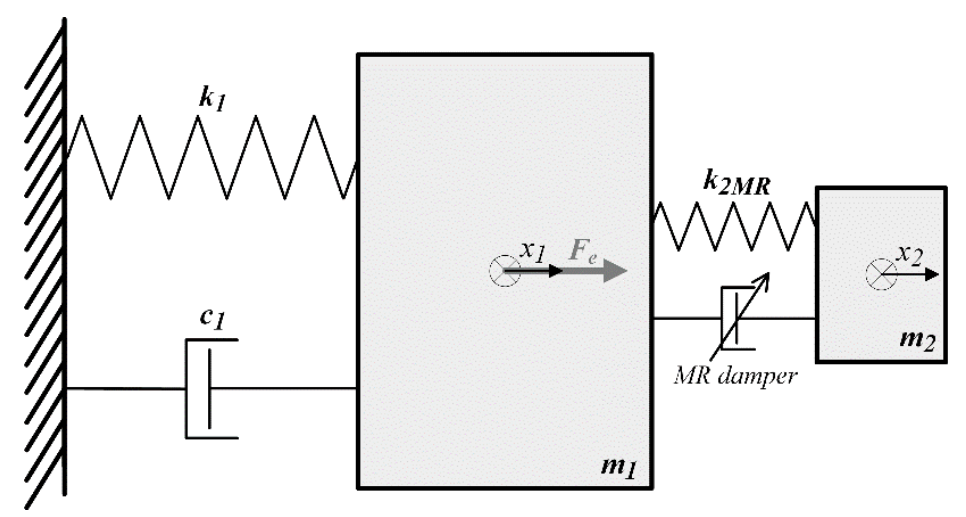

Figure 5. Two-body diagram of a regarded system with magnetorheological TVA (MRTVA).

Table 2. NREL 5.0 MW with MRTVA model parameters.

\begin{tabular}{cc}
\hline Parameter & Value \\
\hline $\mathrm{m}_{1}$ & $428.790 \mathrm{Mg}$ \\
\hline $\mathrm{k}_{1}$ & $1545.6 \mathrm{kN} / \mathrm{m}$ \\
\hline $\mathrm{c}_{1}$ & $3.5420 \mathrm{kNs} / \mathrm{m}$ \\
\hline $\mathrm{m}_{2}$ & $10 \mathrm{Mg}$ \\
\hline $\mathrm{k}_{2 \mathrm{MR}}$ & $30.599 \mathrm{kN} / \mathrm{m}\left(g_{22}=0\right)$ \\
\hline $\mathrm{C}_{1}$ & $29.297 \mathrm{kN} / \mathrm{m}\left(g_{22}>0\right)$ \\
\hline $\mathrm{C}_{2}$ & 3410 \\
\hline $\mathrm{C}_{3}$ & 82.5 \\
\hline $\mathrm{C}_{4}$ & 2640 \\
\hline$v$ & 770 \\
\hline
\end{tabular}

\subsection{Test Conditions}

Test condition parameters are assumed as follows. The wind turbine tower-nacelle model is excited by a harmonic force of a frequency range [0.20, 0.45] $\mathrm{Hz}$ (corresponding to the regarded NREL 5.0 MW towers 1st bending mode frequency neighbourhood) and an amplitude $A\left(F_{e}(t)\right)=21 \mathrm{kN}$, applied horizontally to the nacelle/rotor. A fixed sampling step $t_{s}=10^{-4} \mathrm{~s}$ is adopted, while the optimisation horizon $t_{1}=10 t_{s}$ is assumed, if not stated otherwise.

The weighting factors for the HTVA quality index (6) are assumed concerning (control conf. I-III):

I. minimisation of the primary structure deflection (nacelle-assembly displacement) $x_{1}$ amplitude as the sole objective: $g_{11}=10^{18}, g_{12}=g_{13}=g_{14}=g_{23}=0$, $g_{22}=4 \cdot 10^{-12}$ (additionally, $t_{1}=10^{2} t_{s}$ was regarded);

II. minimisation of the primary structure deflection $x_{1}$ amplitude, considering lower (than for conf. I) deflection amplitude weight with regard to actuator force weight: $g_{11}=5 \cdot 10^{6}, g_{12}=g_{13}=g_{14}=g_{23}=0, g_{22}=4 \cdot 10^{-12}$;

III. minimisation of the primary structure deflection $x_{1}$ amplitude, along with the actuator mean power: $g_{11}=5 \cdot 10^{6}$ (structure deflection vs. actuator force consideration as for conf. II), $g_{12}=g_{13}=g_{14}=0, g_{22}=4 \cdot 10^{-12}, g_{23}=1 \cdot 10^{-10}$ or $g_{23}=4 \cdot 10^{-10}$. 
The nonzero $g_{22}$ value was set for all above configurations to eliminate any divisionby-zero risk in Equation (14) and proposition (15a)-(15c) antecedent.

The weighting factors for the MRTVA quality index (17) are assumed concerning (control conf. IV-V):

IV. minimisation of the primary structure deflection (nacelle-assembly displacement) $x_{1}$ amplitude as the sole objective: $g_{11}=10^{18}, g_{12}=g_{13}=g_{14}=g_{22}=0, g_{21}=4$;

V. minimisation of the primary structure deflection $x_{1}$ amplitude along with the MR damper force: $g_{11}=10^{18}, g_{12}=g_{13}=g_{14}=0, g_{21}=4, g_{22}=1$ or $g_{22}=2$.

\section{Control Results and Discussion}

The efficiency of the HTVA (vs. MRTVA) is analysed employing frequency characteristics of the dynamic amplification factor $(D A F)$ :

$$
D A F=\frac{A\left(x_{1}(t)\right)}{A\left(F_{e}(t)\right) / k_{1}},
$$

as well as the actuator (vs. MR damper) stroke amplitude $A\left(x_{1}-x_{2}\right)$, and the actuators mean power $A P$ and maximum force limit combined with the MR damper maximum force $\operatorname{MRF}(A(\bullet)$ states for amplitude). Moreover, time patterns of the primary structure deflection (nacelle-assembly displacement) $x_{1}$, actuator stroke $x_{1}-x_{2}$, actuator force $F_{a}$, spring force $F_{s}$, and viscous damper force $F_{d}$ are analysed.

Figures 6-11 present the frequency characteristics of $D A F$, and $A\left(x_{1}-x_{2}\right)$, respectively, obtained for the HTVA vs. MRTVA optimal-based control implementations, with regard to the passive TVA. Figures 6-9 combine DAF and $A\left(x_{1}-x_{2}\right)$ frequency characteristics (respectively) obtained for passive TVA vs. HTVA-GH vs. HTVA vs. MRTVA systems. Figures 7-10 present frequency patterns of DAF and $A\left(x_{1}-x_{2}\right)$, respectively, for the HTVA system with different values of $g_{11}$ (the primary structure deflection weight) and $g_{23}$ (the actuator mean power weight). Similarly, Figures 8-11 present $D A F$ and $A\left(x_{1}-x_{2}\right)$ frequency characteristics obtained for the MRTVA system with different $g_{22}$ values (the MR damper force weight). Additionally, Figure 12 presents the actuator mean power frequency characteristics for HTVA with different $g_{11}$ and $g_{23}$ weights vs. HTVA-GH, while Figure 13 combines the MR damper maximum force for MRTVA with different $g_{22}$ values and HTVA actuator force limit of $3.0 \mathrm{kN}$.

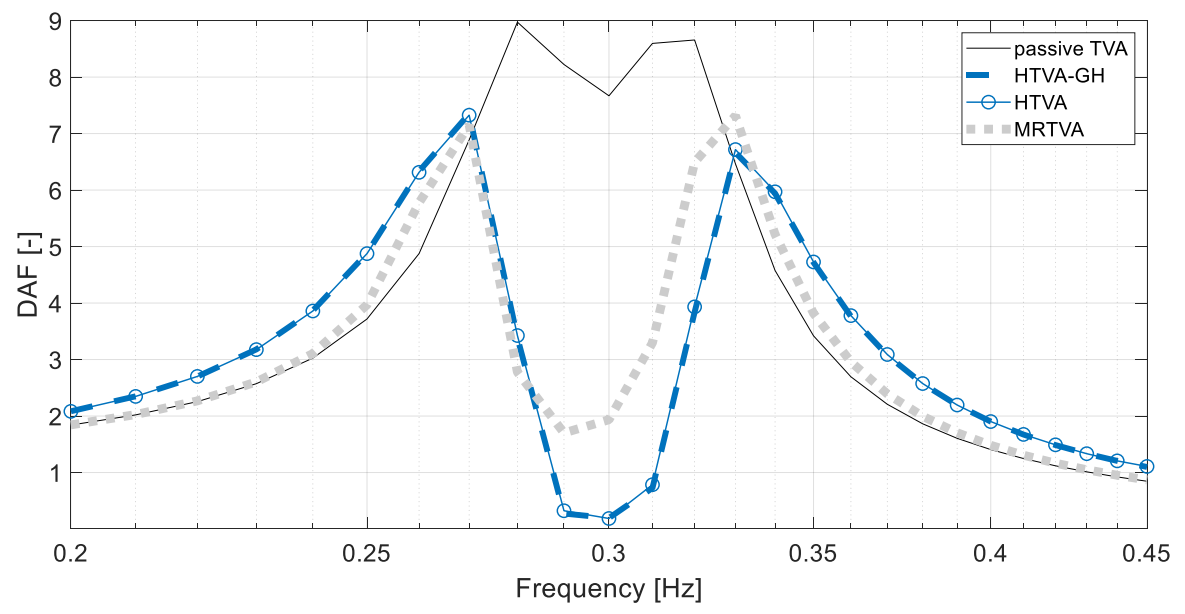

Figure 6. Dynamic Amplification Factor $(D A F)$ frequency characteristics: passive TVA vs. HTVA-GH vs. $\operatorname{HTVA}\left(g_{11}=10^{18}, g_{23}=0, t_{1}=10^{2} t_{s}\right)$ vs. MRTVA $\left(g_{22}=0\right)$. 


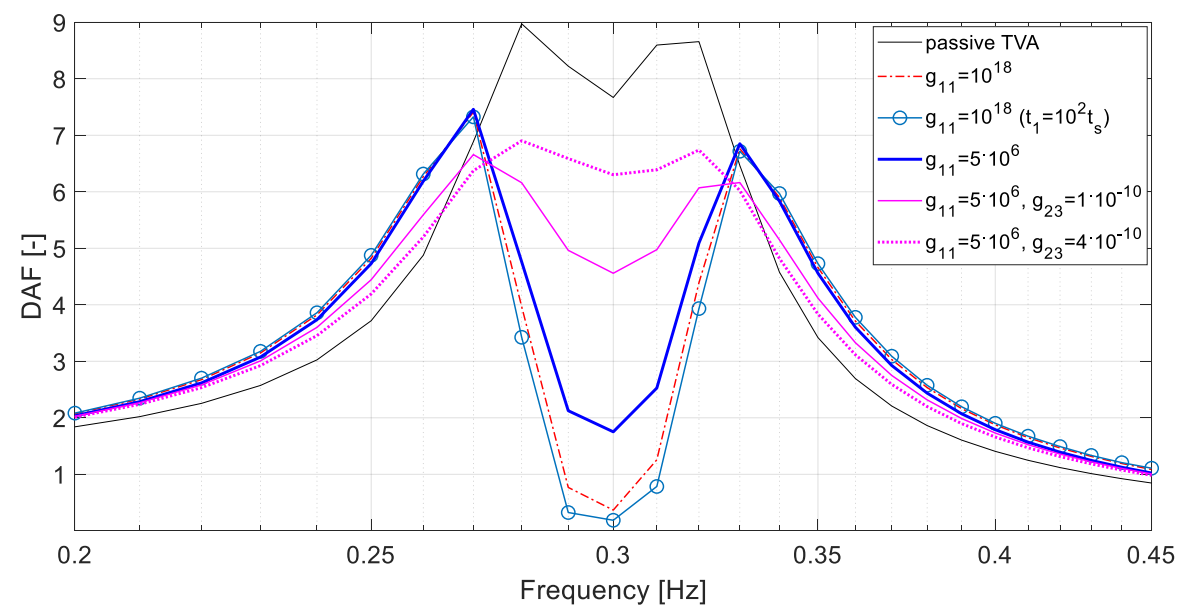

Figure 7. DAF frequency characteristics: passive TVA vs. HTVA with different $g_{11}$ and $g_{23}$ values $\left(g_{23}=0\right.$, if not stated otherwise).

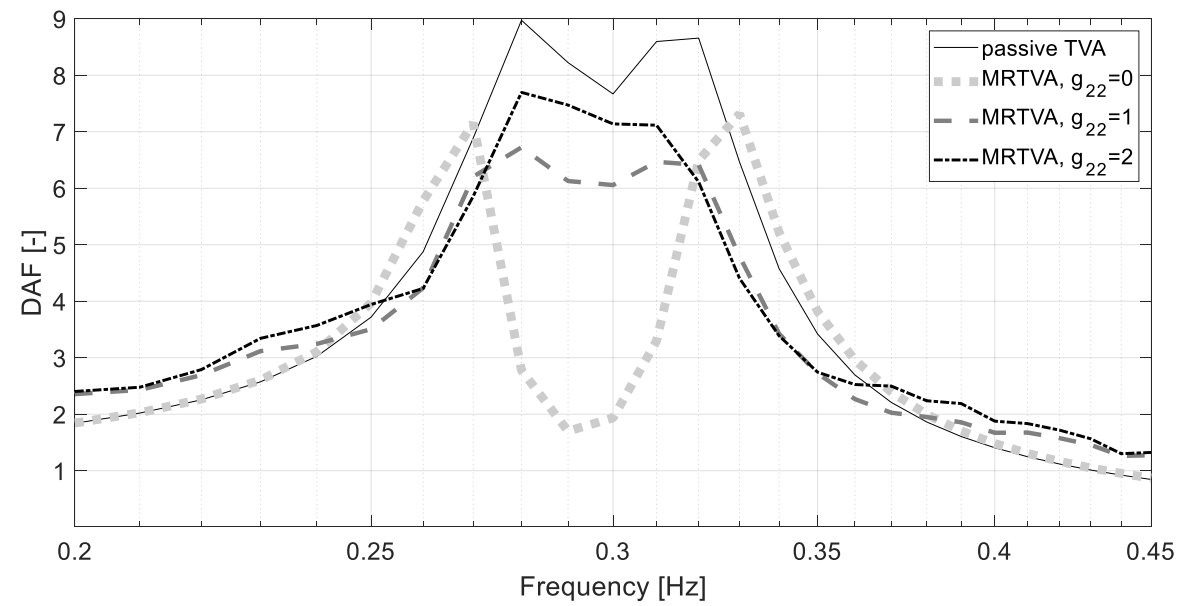

Figure 8. $D A F$ frequency characteristics: passive TVA vs. MRTVA with different $g_{22}$ values.

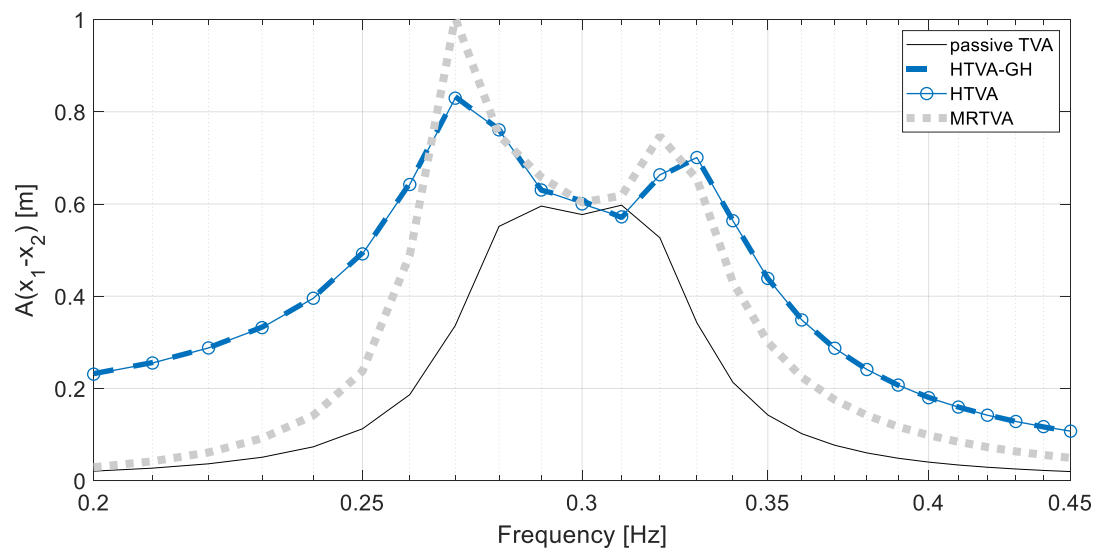

Figure 9. The TVA stroke amplitude $A\left(x_{1}-x_{2}\right)$ frequency characteristics: passive TVA vs. HTVA-GH vs. $\operatorname{HTVA}\left(g_{11}=10^{18}, g_{23}=0, t_{1}=10^{2} t_{s}\right)$ vs. $\operatorname{MRTVA}\left(g_{22}=0\right)$. 


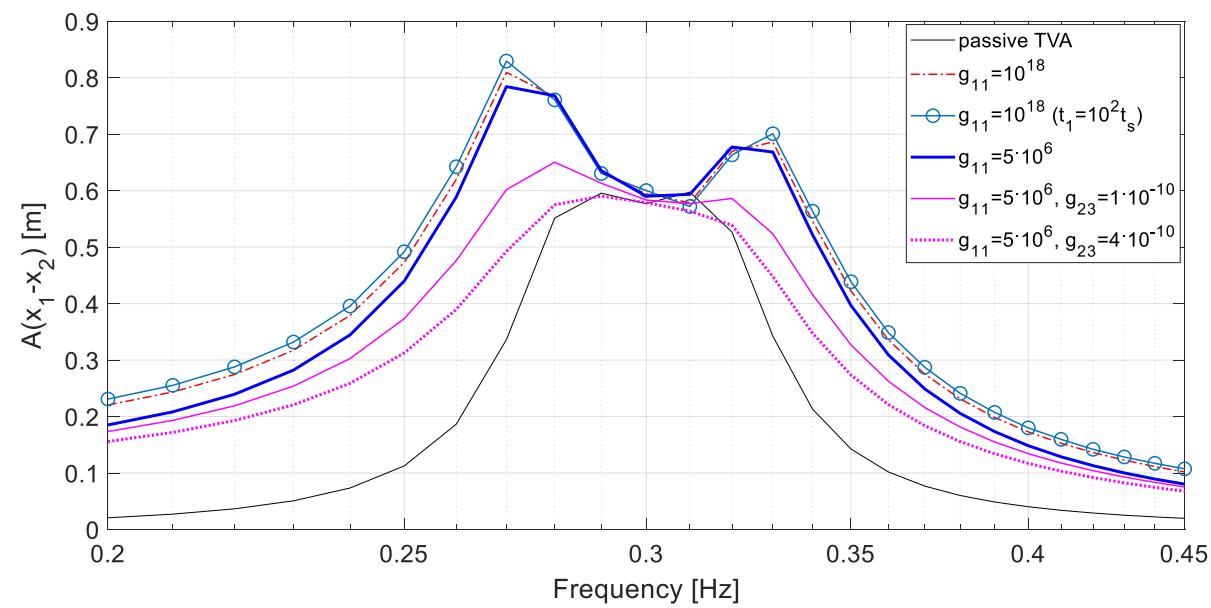

Figure 10. $A\left(x_{1}-x_{2}\right)$ frequency characteristics: passive TVA vs. HTVA with different $g_{11}$ and $g_{23}$ values $\left(g_{23}=0\right.$, if not stated otherwise).

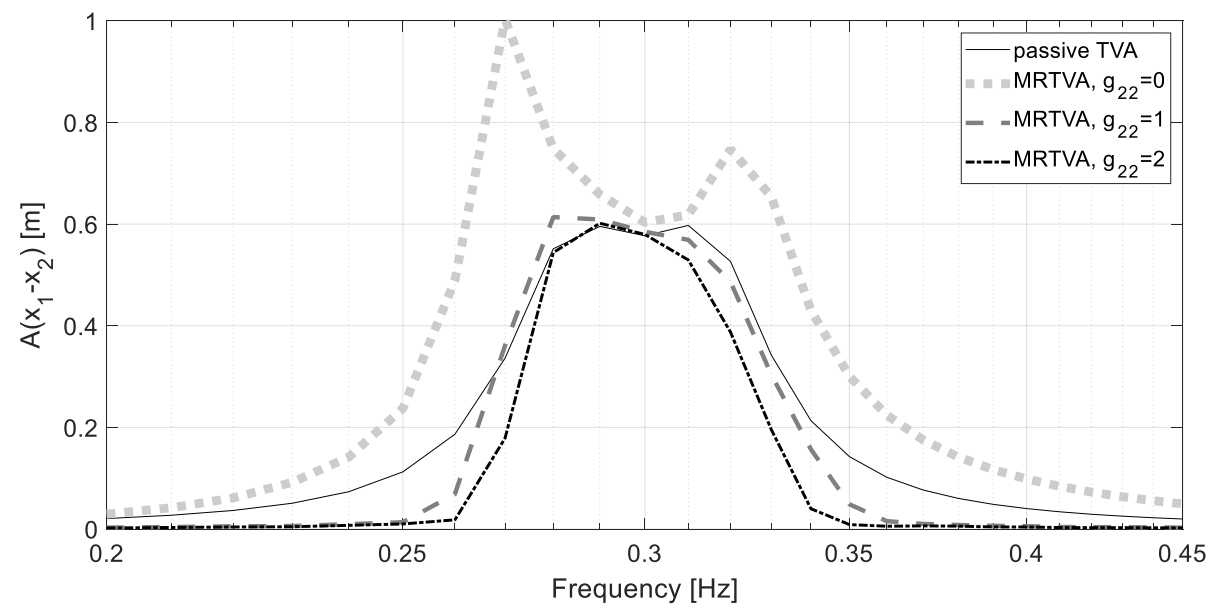

Figure 11. $A\left(x_{1}-x_{2}\right)$ frequency characteristics: passive TVA vs. MRTVA with different $g_{22}$ values.

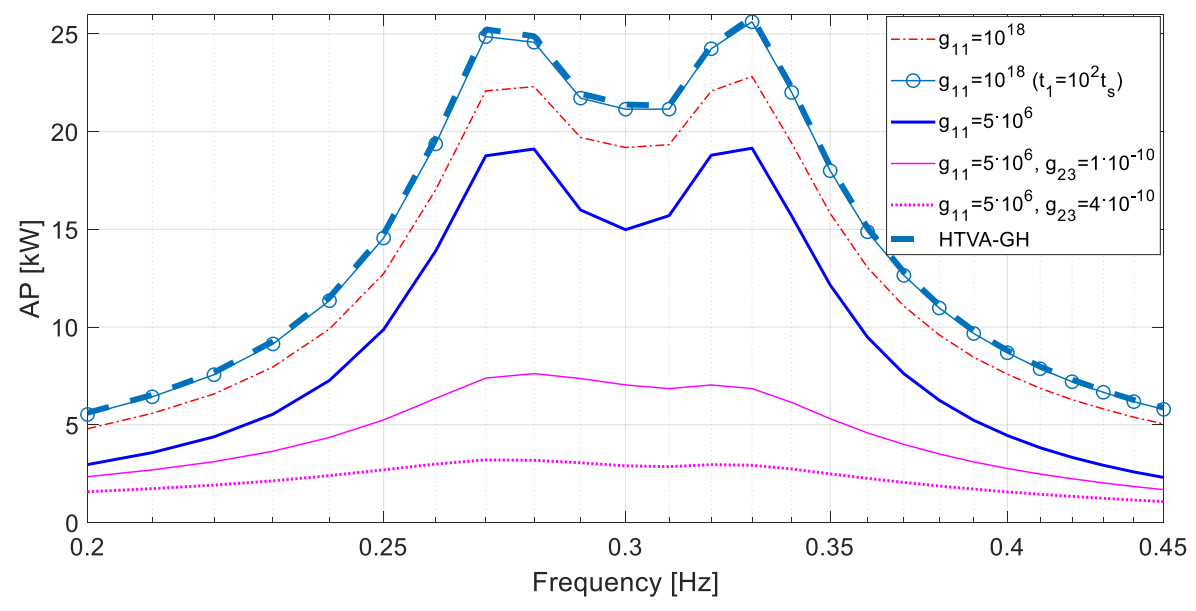

Figure 12. The actuator mean power AP frequency characteristics: HTVA with different $g_{11}$ and $g_{23}$ values $\left(g_{23}=0\right.$, if not stated otherwise) vs. HTVA-GH. 


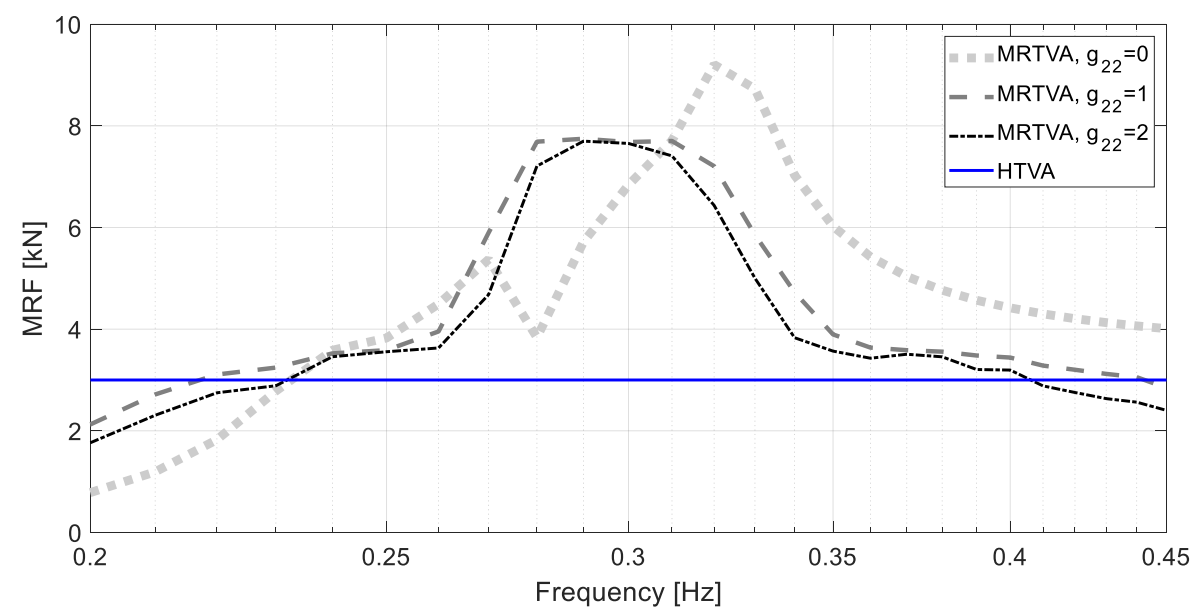

Figure 13. The MR damper maximum force $M R F$ frequency characteristics: $M R T V A$ with different $g_{22}$ values vs. HTVA actuator maximum force limit.

Figures 14-16 present the comparison of the $x_{1}, x_{1}-x_{2}, F_{a}, F_{s}$, and $F_{d}$ time patterns obtained for HTVA, HTVA-GH, and passive TVA systems at the frequency points of: $0.27 \mathrm{~Hz}, 0.28 \mathrm{~Hz}$ and $0.30 \mathrm{~Hz}$ (see $D A F$ and $A\left(x_{1}-x_{2}\right)$ values at these frequency points in Figures 6-10). Time patterns obtained for the MRTVA system are presented in [33,34].

Observing the comparison of $D A F$ frequency characteristics in Figure 6, it is evident that implementation of both HTVA (either HTVA-GH, or HTVA) with $3.0 \mathrm{kN}$ actuator, and MRTVA with MRF of $9.2 \mathrm{kN}$, leads to significant NREL 5.0 MW tower vibration reduction in comparison to a system with a passive TVA of the same absorber mass ratio. However, HTVA (HTVA-GH, and HTVA conf. I), due to its active force of the demanded value and sign, is capable of lowering $D A F$ almost to zero in the 1st tower bending frequency (ca. $3.0 \mathrm{~Hz}$ ) neighbourhood, where optimal damping ratio is zero. In contrast, MRTVA (conf. IV) lowers the DAF value to ca. 1.8, as the MR damper residual force at zero current is always nonzero, and the force sign is arbitrary. Maximum DAF values for both HTVA and MRTVA are ca. 7.3. Yet, these values of DAF are quite satisfactory for the $2.33 \%$ TVA mass ratio. In comparison, minimum and maximum $D A F$ values within the 1st bending frequency neighbourhood for passive TVA are 7.7 and 9.0, respectively. The influence of $g_{11}$ (the tower deflection weight) and $g_{23}$ (the actuator mean power weight) values on $D A F$ is evident in Figure 7. The weighting factors of the conf. I yield the most favourable $D A F$ patterns; however, this comes at the cost of the longest TVA stroke required (as for HTVA-GH, see Figures 9 and 10) and, especially, the highest mean power/energy demand (although slightly lower than for HTVA-GH, Figure 12). The conf. II yields a somewhat higher minimum $D A F$ within the 1st bending frequency neighbourhood, but the TVA stroke is slightly lower, while the power/energy demand is significantly reduced. Finally, the conf. III yields raised minimum $D A F$ values within the 1st bending frequency neighbourhood, although maximum $D A F$ values are, on the other hand, lowered below 7.0; moreover, stroke amplitudes are considerably reduced-even below $0.6 \mathrm{~m}\left(g_{23}=4 \cdot 10^{-10}\right.$; ca. $30 \%$ reduction with regard to conf. $\left.I, t_{1}=10^{2} t_{s}\right)$-similar to passive TVA, while the demanded energy is reduced massively ( 8 -fold for $g_{23}=4 \cdot 10^{-10}$ with regard to conf. $I, t_{1}=10^{2} t_{s}$ ). Concerning the MRTVA dependence on the MR damper force weight, setting nonzero $g_{22}$, conf. $V$ (vs. $g_{22}=0$, conf. $I V$ ) yields DAF patterns (Figure 8 ) with the local minimum value raised, lowered two maxima for $g_{22}=1$ (see comment above for conf. III), and leads to an ca. $16 \%$ reduction in the maximum demanded MR damper force (see Figure 13) and, at the same time, $40 \%$ reduction in the damper stroke amplitude (Figure 11). Maximum $A\left(x_{1}-x_{2}\right)$ values for conf. $V$ are similar to both passive TVA and HTVA conf. III with $g_{23}=4 \cdot 10^{-10}$ (Figure 10). 


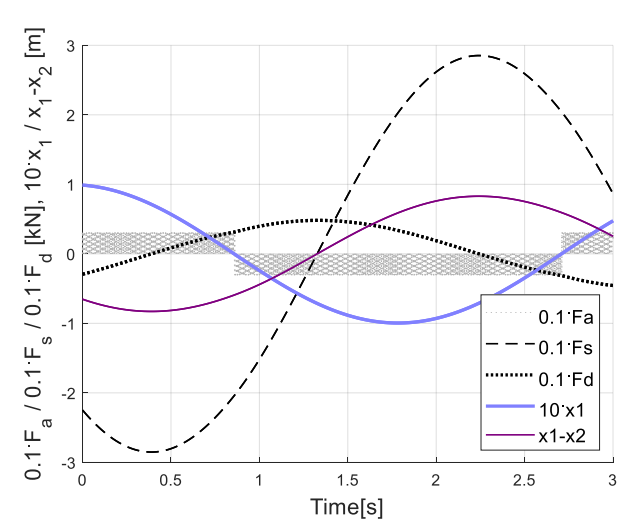

(a)

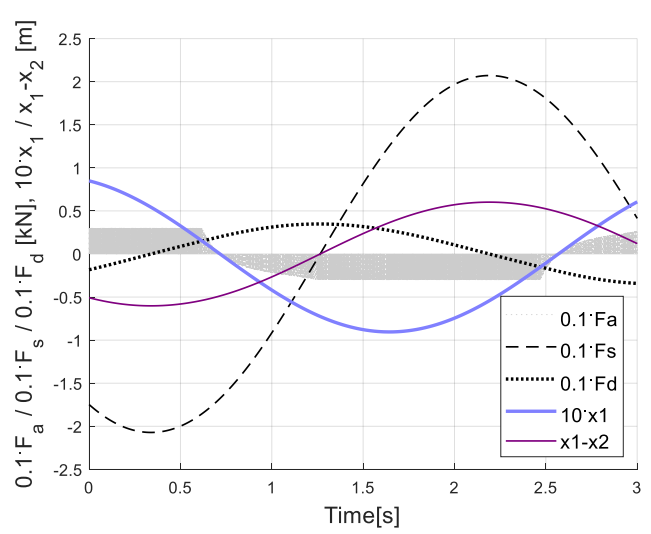

(c)

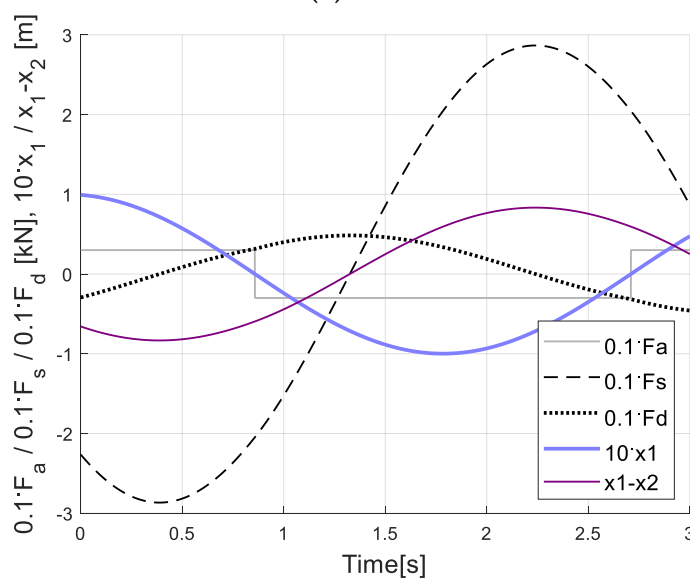

(e)

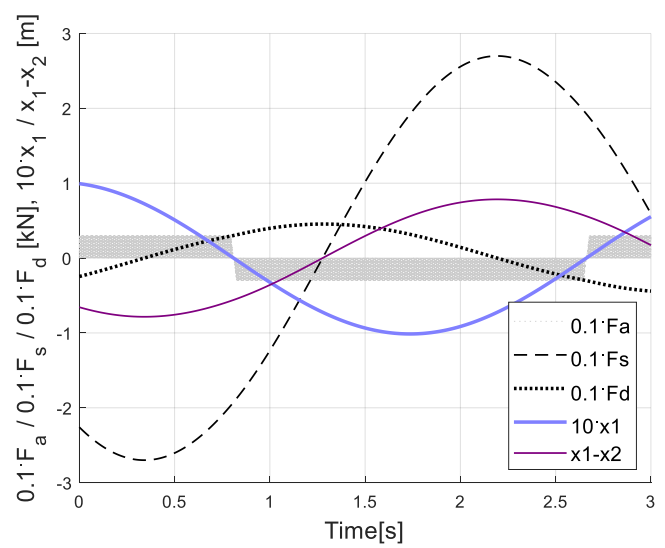

(b)

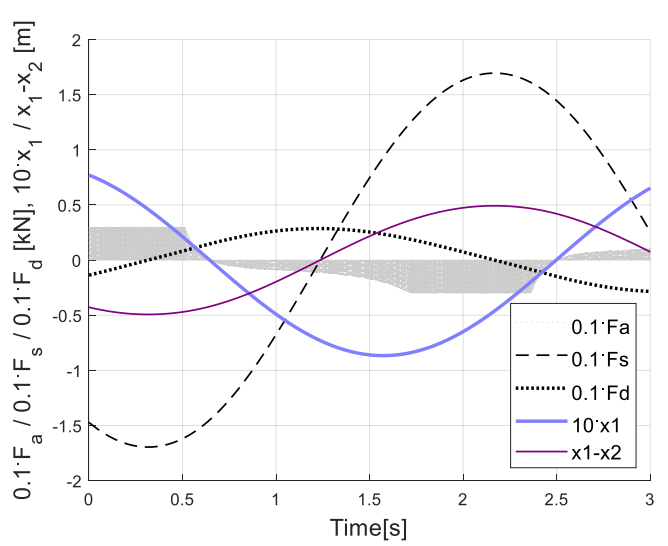

(d)

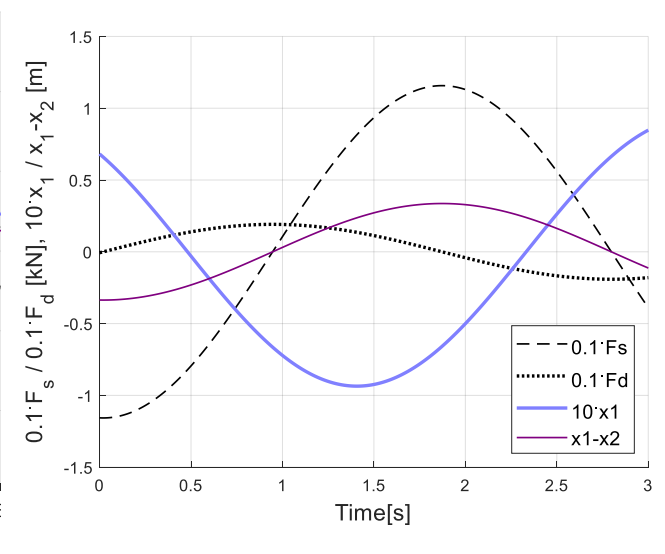

(f)

Figure 14. Time responses at $0.27 \mathrm{~Hz}$ : (a) HTVA, $g_{11}=10^{18}, g_{23}=0, t_{1}=10^{2} t_{s}$, (b) HTVA, $g_{11}=5 \cdot 10^{6}, g_{23}=0$, (c) HTVA, $g_{11}=5 \cdot 10^{6}, g_{23}=1 \cdot 10^{-10}$, (d) HTVA, $g_{11}=5 \cdot 10^{6}, g_{23}=4 \cdot 10^{-10}$, (e) HTVA-GH, (f) passive TVA. 


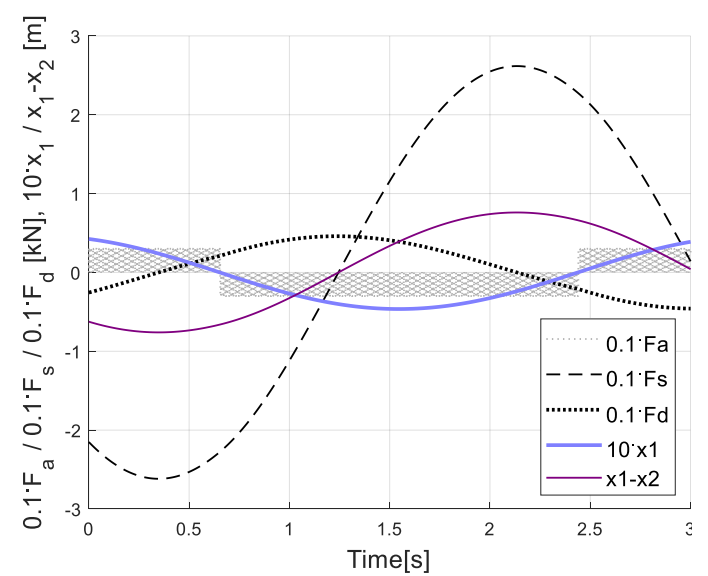

(a)

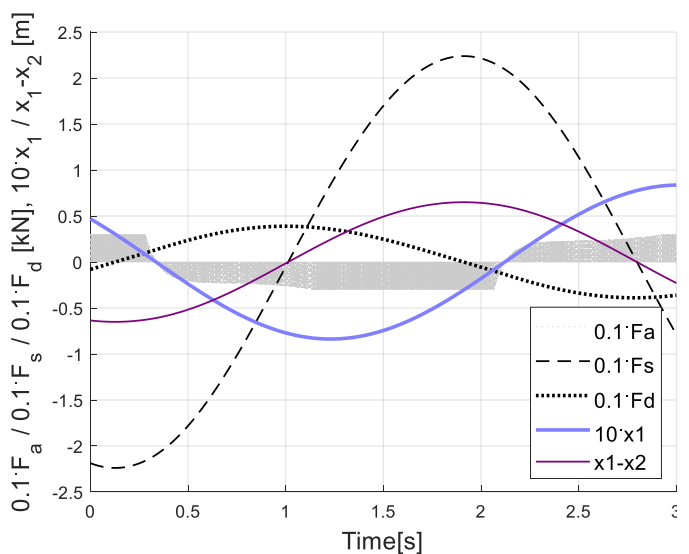

(c)

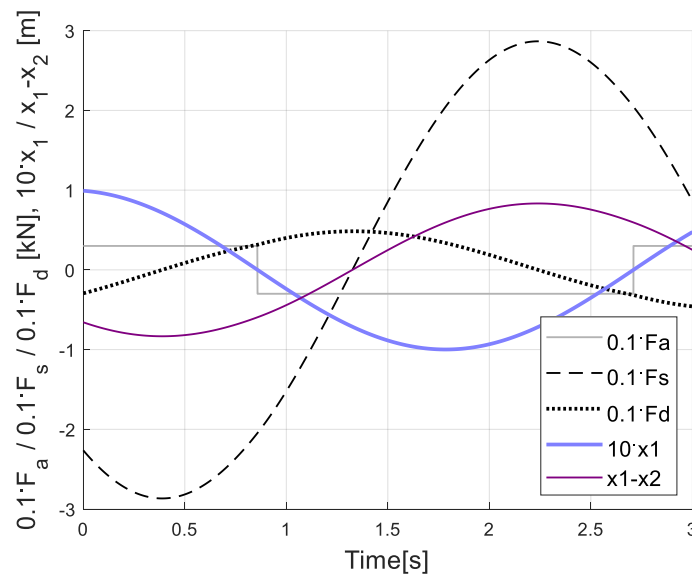

(e)

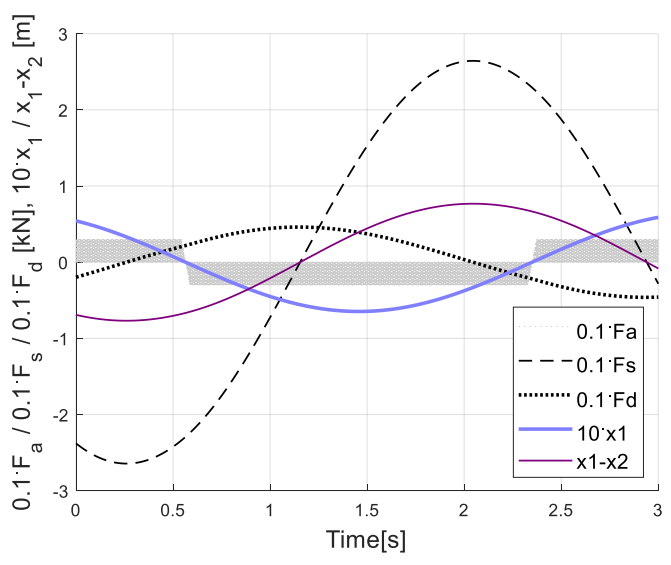

(b)

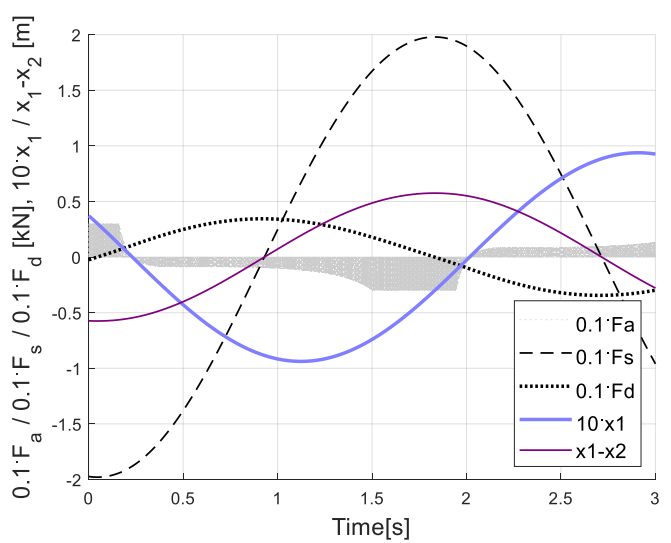

(d)

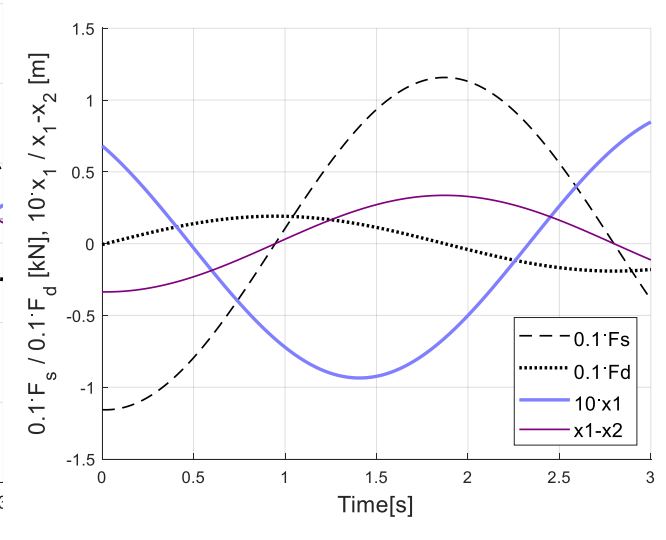

(f)

Figure 15. Time responses at $0.28 \mathrm{~Hz}$ : (a) HTVA, $g_{11}=10^{18}, g_{23}=0, t_{1}=10^{2} t_{s}$, (b) HTVA, $g_{11}=5 \cdot 10^{6}, g_{23}=0$, (c) HTVA, $g_{11}=5 \cdot 10^{6}, g_{23}=1 \cdot 10^{-10},(\mathbf{d}) H T V A, g_{11}=5 \cdot 10^{6}, g_{23}=4 \cdot 10^{-10},(\mathbf{e})$ HTVA-GH, (f) passive TVA. 


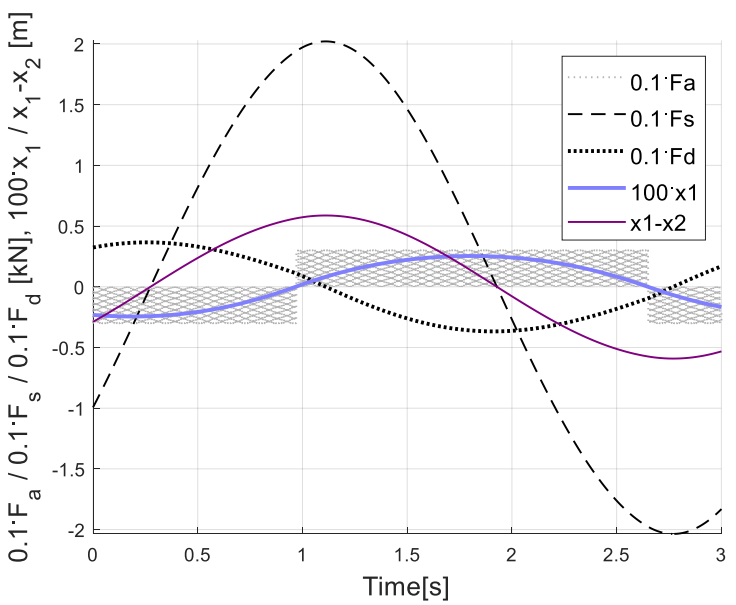

(a)

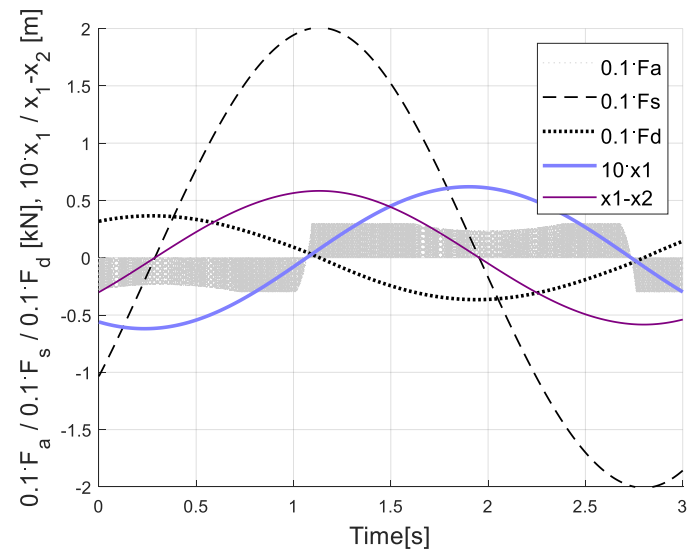

(c)

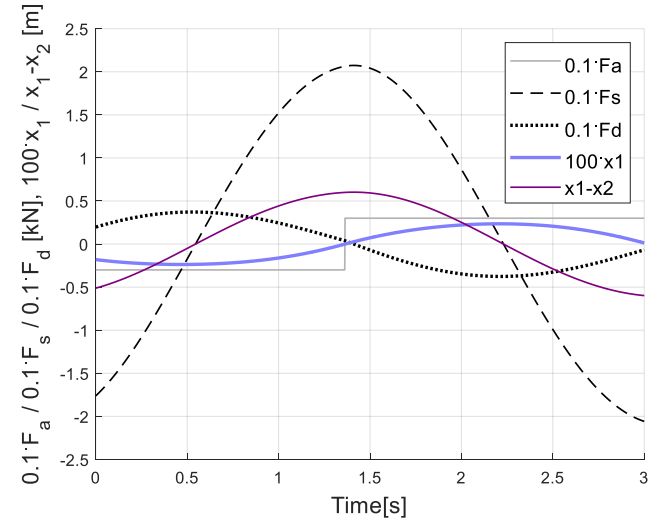

(e)

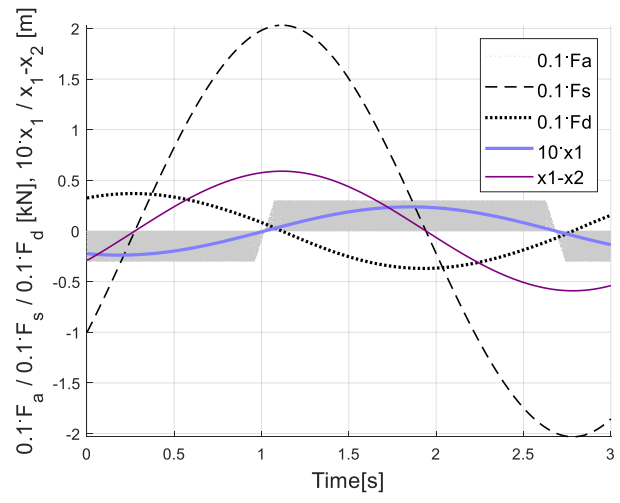

(b)

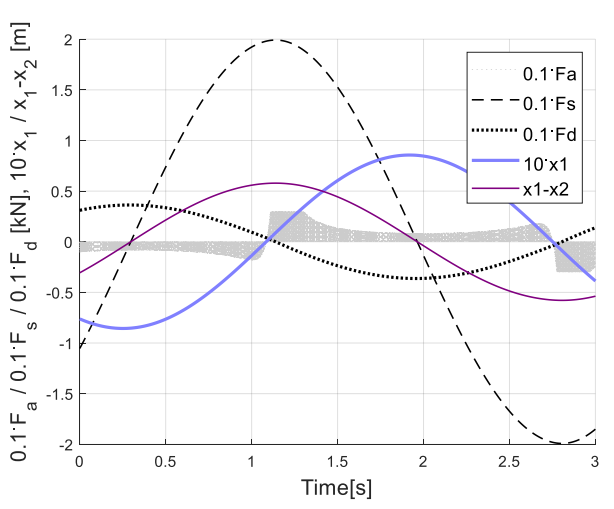

(d)

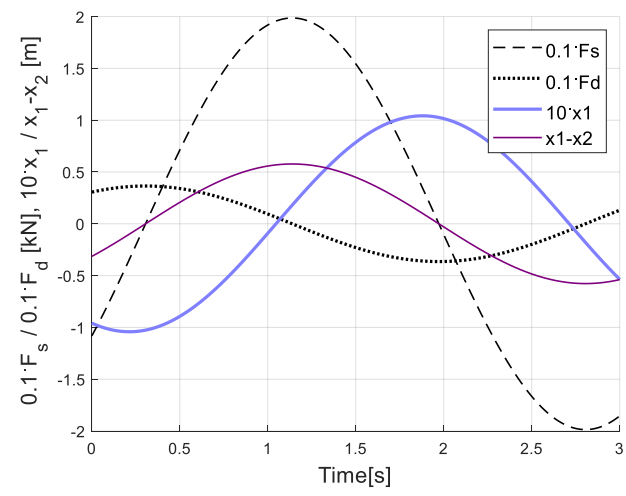

(f)

Figure 16. Time responses at $0.30 \mathrm{~Hz}$ : (a) HTVA, $g_{11}=10^{18}, g_{23}=0, t_{1}=10^{2} t_{s},(\mathbf{b}) H T V A, g_{11}=5 \cdot 10^{6}, g_{23}=0$, (c) HTVA, $g_{11}=5 \cdot 10^{6}, g_{23}=1 \cdot 10^{-10}$, (d) HTVA, $g_{11}=5 \cdot 10^{6}, g_{23}=4 \cdot 10^{-10}$, (e) HTVA-GH, (f) passive TVA.

It may be concluded that both HTVA and MRTVA yield tower vibration reduction compared to the passive TVA. The highest DAF reduction efficiency is observed for HTVA conf. I and HTVA-GH with a $0.83 \mathrm{~m}$ stroke amplitude and $3.0 \mathrm{kN}$ actuator force $/ 25.6 \mathrm{~kW}$ mean actuator power. The best MRTVA based solution is conf. IV with the $1.0 \mathrm{~m}$ stroke amplitude and $9.2 \mathrm{kN}$ MR damper maximum force. Concerning $D A F$, the advantage of HTVA solutions (HTVA-GH, and HTVA conf. I) over MRTVA (conf. IV) is evident within the 1 st tower bending frequency $-5 /+10 \%$ neighbourhood (Figure 6 ), using $17 \%$ less working space (Figure 9); however, MRTVA uses only minimal (signal level) energy, to amend MR damper operating properties, as compared with HTVA. The interesting alternatives are 
HTVA conf. III, and MRTVA conf. $V$ with $g_{22}=1$. Compared with the passive TVA, they require similar working space, while $D A F$ reduction is quite significant. The actuator mean power in conf. III is as low as $7.6 \mathrm{~kW}$ or even $3.2 \mathrm{~kW}\left(g_{23}=1 \cdot 10^{-10}\right.$ or $g_{23}=4 \cdot 10^{-10}$, respectively), while the required MR damper force for conf. $V$ is ca. $7.7 \mathrm{kN}$. In conclusion, by increasing the $g_{23}$ weight of HTVA (or $g_{22}$ weight of MRTVA), effective vibration attenuation is obtained with reduced mean actuator power (or reduced MR damper force); thanks to this, reasonable performance is attainable using a significantly (8-fold) lower energy amount (or MR damper characterised with 16\% lower resistance force).

Time patterns presented in Figures 14-16 give the possibility to compare control force $F_{a}$ characteristics, as well as the effectiveness of HTVA with different $g_{11}$ and $g_{23}$ values $(\mathrm{a} \div \mathrm{d})$ and HTVA-GH (e), combined with passive TVA (f). Both HTVA conf. I (a) and conf. II (b) are distinguished by high-frequency bang-bang $\left(0, \pm F_{\text {sat }}\right)$ control patterns, although for lower $g_{11}$ value (conf. II), very short transition time ranges corresponding to the proposition (15c) may be observed. HTVA conf. I (a) (corresponding to the highest $g_{11}$ weight) along with HTVA-GH (e) both exhibit the best $A\left(x_{1}\right)$ reduction efficiency overall, especially at $0.30 \mathrm{~Hz}$ excitation frequency (Figure 16, mind different ordinate labels for (a) and (e)). The difference in HTVA conf. I (a) and HTVA-GH (e) control patterns (high-frequency high-duty-cycle bang-bang switches vs. simple bang-bang switches) yield slightly lower mean actuator power (energy demand) for HTVA conf. I. The influence of nonzero $g_{23}$ is evident when observing HTVA conf. III control $F_{a}$ patterns (c) and (d), characterised with the actuator force trimming that is more evident for greater $g_{23}$ value $(\mathrm{d})$, yielding significantly reduced mean actuator power (Figure 12) and hence energy demand.

The greater the (H)TVA stroke amplitude $A\left(x_{1}-x_{2}\right)$ (that is influenced by the control force $F_{a}$ pattern), the higher the spring force component $F_{S}$ and (for the same frequency) viscous damper force component $F_{d}$. Based on Figures $14-16$, it may be seen that $F_{a}$ is set in phase with $x_{1}$, which confirms (29). Considering the $F_{a}$ sign in (5) indicates that control force $F_{a}$ opposes primary structure deflection $x_{1}$.

\section{Conclusions}

The current research aimed to compare the optimal-based vibration control solutions for the wind turbine towers 1st bending mode, utilising the tower-nacelle model of the NREL 5.0 MW wind turbine equipped with a nonlinear HTVA vs. MRTVA. Employing the Pontryagin maximum principle, the nonlinear optimal HTVA control proposition was derived along with its simplified revisions to avoid high computational load $B V P$ solving during real-time control. The developed techniques were successfully implemented and verified by simulation analyses against the previously developed MRTVA control solution. The derived simple optimal-based hybrid ground-hook control (HTVA-GH) and the proposed optimal-based nonlinear control (HTVA) tuned with the aim of the primary structure deflection minimisation priority provided the best vibration attenuation efficiency. The advantage of HTVA over MRTVA is evident within the 1st tower bending frequency $(3.0 \mathrm{~Hz}$ ) neighbourhood (see Figure 6), with HTVA also requiring less working space.

Using the appropriate optimisation fields of a nonlinear optimal control quality index enabled an 8-fold reduction of the HTVA mean actuator power along with a (further) $29 \%$ reduction of the working space while maintaining a significant advantage of HTVA (concerning $D A F$ ) over the passive TVA. The attained $D A F$ values are more than adequate for the assumed $2.33 \%$ mass ratio and $3.0 \mathrm{kN}$ actuator force, proving the effectiveness and validity of the proposed approaches.

Although the above results are obtained using the simplified 2 DOF tower-nacelle model with HTVA, the developed control solutions may be implemented in many engineering structures and systems such as onshore and offshore wind turbines, high-rise buildings, masts, bridges, etc. Both HTVA and HTVA-GH do not require determination of the actual (dominant) vibration frequency or mode, excitation or disturbance assumptions, nor the specification of the protected structure/system nature; the HTVA has to be tuned accordingly using modal parameters (mass and stiffness) associated with the protected 
structure/system selected mode, whereas for the HTVA proposition (15a)-(15c), state and co-state dynamics model (representing the selected mode and HTVA) is also required. The produced control signal is directly the actuator input, i.e., the voltage in the regarded example (in addition to the calculation of the required active force), as actuator nonlinearity is an intrinsic part of the control proposition derived for the sample actuator characteristics. No force tracking nor offline calculations are necessary. Thus, the control quality is not compromised by excitation/disturbance variation or actuator force constraints, both essential for real-time control.

The method limitation is the HTVA location-it should be optimised with regard to the particular vibration mode deflection maximum, e.g., for the 1st tower bending mode attenuation, TVA should be preferably localised in the nacelle or top tower section, while for the 2 nd tower bending mode attenuation-at $0.6 \div 0.7$ height of the tower. It is apparent $[11,14]$ that the second tower bending mode node occurs very close to the nacelle location; thus, vibration attenuation possibilities using the TVA located in the nacelle are little to moderate. Also, when the vibration frequency deviates significantly from the frequency of HTVA tuning, the stiffness (spring) force has to be amended by the active actuator to re-tune the HTVA; thus, the HTVA efficiency is limited for such a case by an actuator force constraints in relation to the magnitude of the frequency deviation.

The derived HTVA-GH algorithm is devoted to the case when only the primary structure deflection amplitude has to be minimised, while the HTVA proposition (15a)-(15c) copes well with various minimisation fields covered by the quality index (6) as, e.g., primary structure deflection, velocity, or (indirectly-with the use of dynamics (5)) acceleration, actuator stroke (working space), velocity, force, or energy demand; all may be encountered during real-world wind turbine operation. Only some of these fields were optimised within the current research. However, the proposed approach will serve as a general platform for future widespread analyses covering, e.g., actuator velocity and acceleration restrictions, root-mean-square vs. peak force limitation, protected structure acceleration minimisation, etc. The nearest stage of the author's research is the experimental validation of the proposed solution using a scaled laboratory model of a wind turbine tower-nacelle system [51,52] that exhibits dynamical similarity with a full-scale wind turbine structure [53].

Funding: This research was funded by AGH University of Science and Technology, research program number 16.16.130.942.

Conflicts of Interest: The author declares no conflict of interest.

\section{References}

1. Xu, Z.-D.; Zhu, J.-T.; Wang, D.-X. Analysis and Optimisation of Wind-Induced Vibration Control for High-Rise Chimney Structures. Int. J. Acoust. Vib. 2014, 19. [CrossRef]

2. Wang, X.; Gordaninejad, F. Lyapunov-Based Control of a Bridge Using Magneto-rheological Fluid Dampers. J. Intell. Mater. Syst. Struct. 2002, 13, 7-8. [CrossRef]

3. Weber, F.; Maslanka, M. Precise stiffness and damping emulation with MR dampers and its application to semi-active tuned mass dampers of Wolgograd Bridge. Smart Mater. Struct. 2014, 23, 15019. [CrossRef]

4. Bakhtiari-Nejad, F.; Meidan-Sharafi, M. Vibration Optimal Control of a Smart Plate with Input Voltage Constraint of Piezoelectric Actuators. J. Vib. Control 2004, 10, 1749-1774. [CrossRef]

5. Ali, S.F.; Ramaswamy, A. Hybrid structural control using magnetorheological dampers for base isolated structures. Smart Mater. Struct. 2009, 18. [CrossRef]

6. Esteki, K.; Bagchi, A.; Sedaghati, R. Semi-Active Tuned Mass Damper for Seismic Applications. In Proceedings of the International Workshop Smart Materials, Structures \& NDT in Aerospace Inter-digitized Transducers (IDTS) for Integrated Structural Health Monitoring (ISHM) Applications, Montreal, QC, Canada, 2-4 November 2011.

7. Kucuk, I.; Yıldırım, K.; Sadek, I.; Adali, S. Optimal control of a beam with Kelvin-Voigt damping subject to forced vibrations using a piezoelectric patch actuator. J. Vib. Control 2013, 21, 701-713. [CrossRef]

8. Caterino, N. Semi-active control of a wind turbine via magnetorheological dampers. J. Sound Vib. 2015, 345, 1-17. [CrossRef]

9. Enevoldsen, I.; Mørk, K.J. Effects of a Vibration Mass Damper in a Wind Turbine Tower*. Mech. Struct. Mach. 1996, $24,155-187$. [CrossRef] 
10. Kirkegaard, P.H.; Nielsen, S.R.K.; Poulsen, B.L.; Andersen, J.; Pedersen, L.H.; Pedersen, B.J. Semiactive Vibration Control of a Wind Turbine Tower using an MR Damper. In Structural Dynamics—EURODYN; Grundmann, H., Schueller, G.I., Eds.; Swets \& Zeitlinger: Lisse, Switzerland, 2002.

11. Nguyen, T.-C.; Huynh, T.-C.; Kim, J.-T. Numerical evaluation for vibration-based damage detection in wind turbine tower structure. Wind. Struct. Int. J. 2015, 21, 657-675. [CrossRef]

12. Bir, G.; Jonkman, J. Aeroelastic Instabilities of Large Offshore and Onshore Wind Turbines. J. Phys. Conf. Ser. 2007, 75, 012069. [CrossRef]

13. Hansen, M.H.; Fuglsang, P.; Thomsen, K.; Knudsen, T. Two Methods for Estimating Aeroelastic Damping of Operational Wind Turbine Modes from Experiments. In Proceedings of the European Wind Energy Association Annual Event, Copenhagen, Denmark, 16-19 April 2012.

14. Butt, U.A.; Ishihara, T. Seismic Load Evaluation of Wind Turbine Support Structures Considering Low Structural Damping and Soil Structure Interaction. In Proceedings of the European Wind Energy Association Annual Event, Copenhagen, Denmark, 16-19 April 2012.

15. Matachowski, F.; Martynowicz, P. Analiza dynamiki konstrukcji elektrowni wiatrowej z wykorzystaniem środowiska Comsol Multiphysics. Modelowanie Inżynierskie 2012, 44, 209-216.

16. Martynowicz, P. Study of vibration control using laboratory test rig of wind turbine tower-nacelle system with MR damper based tuned vibration absorber. Bull. Pol. Acad. Sci. Tech. Sci. 2016, 64, 347-359. [CrossRef]

17. Martynowicz, P. Vibration control of wind turbine tower-nacelle model with magnetorheological tuned vibration absorber. J. Vib. Control 2015, 23, 3468-3489. [CrossRef]

18. Martynowicz, P. Control of an MR Tuned Vibration Absorber for Wind Turbine Application Utilising the Refined Force Tracking Algorithm. J. Low Freq. Noise Vib. Act. Control 2017, 36, 339-353. [CrossRef]

19. Martynowicz, P.; Santos, M. Structural vibration control of NREL 5.0 MW FOWT using optimal-based MR tuned vibration absorber. In Proceedings of the 21st IFAC World Congress, Berlin, Germany, 11-17 July 2020.

20. Martynowicz, P.; Rosół, M. Wind Turbine Tower-Nacelle System with MR Tuned Vibration Absorber: Modelling, Test Rig, and Identification. In Proceedings of the ICCC 2019 20th International Carpathian Control Conference, Kraków, Poland, 26-29 May 2019.

21. Rosół, M.; Martynowicz, P. Identification of the Wind Turbine Model with MR Damper Based Tuned Vibration Absorber. In Proceedings of the ICCC 2019 20th International Carpathian Control Conference, Kraków, Poland, 26-29 May 2019.

22. Demetriou, D.; Nikitas, N. A Novel Hybrid Semi-Active Mass Damper Configuration for Structural Applications. Appl. Sci. 2016, 6, 397. [CrossRef]

23. Den Hartog, J.P. Mechanical Vibrations; Dover Publications: Mineola, NY, USA, 1985.

24. Kim, J.T.; Yun, C.B.; Park, J.H. Thermal effects on modal properties and frequency-based damage detection in plate-girder bridges. Proc. SPIE 2004, 5391, 400-409.

25. Rotea, M.A.; Lackner, M.A.; Saheba, R. Active Structural Control of Offshore Wind turbines. In Proceedings of the 48th AIAA Aerospace Sciences Meeting Including the New Horizons Forum and Aerospace Exposition, Orlando, FL, USA, 4-7 January 2010.

26. Preumont, A.; Alaluf, D.; Bastaits, R. Hybrid Mass Damper: A Tutorial Example. In Active and Passive Vibration Control of Structures; Hagedorn, P., Spelsberg-Korspeter, G., Eds.; CISM International Centre for Mechanical Sciences: Udine, Italy, 2014. [CrossRef]

27. Kavyashree, B.; Patil, S.; Rao, V.S. Review on vibration control in tall buildings: From the perspective of devices and applications. Int. J. Dyn. Control 2020, 9, 1316-1331. [CrossRef]

28. Spencer, B.F., Jr.; Soong, T.T. New Applications and Development of Active, Semi-Active and Hybrid Control Techniques for Seismic and Non-Seismic Vibration in the USA. In Proceedings of the International Post-SMiRT Conference Seminar on Seismic Isolation, Passive Energy Dissipation and Active Control of Vibration of Structures, Cheju, Korea, 19-21 May 1999.

29. Koo, J.H.; Ahmadian, M. Qualitative Analysis of Magneto-Rheological Tuned Vibration Absorbers: Experimental Approach. J. Intell. Mater. Syst. Struct. 2007, 18, 1137-1142. [CrossRef]

30. Kciuk, S.; Martynowicz, P. Special application magnetorheological valve numerical and experimental analysis. Control engineering in materials processing, Diffusion and Defect Data-Solid State Data. Part B Solid State Phenom. 2011, 177, 102-115. [CrossRef]

31. Sapiński, B.; Rosół, M. MR damper performance for shock isolation. J. Theor. Appl. Mech. 2017, 45, $133-145$.

32. Krysinski, T.; Ferullo, D.; Roure, A. Helicopter vibration control methodology and flight test validation of a self-adaptive anti-vibration system. In Proceedings of the 24th European Rotorcraft Forum, Marseille, France, 15-17 September 1998.

33. Martynowicz, P. Nonlinear optimal-based vibration control for systems with MR tuned vibration absorbers. J. Low Freq. Noise Vib. Act. Control 2019, 38, 1607-1628. [CrossRef]

34. Martynowicz, P. Real-time implementation of nonlinear optimal-based vibration control for a wind turbine model. J. Low Freq. Noise Vib. Act. Control 2018, 38, 1635-1650. [CrossRef]

35. Nakamura, Y.; Tanaka, K.; Nakayama, M.; Fujita, T. Hybrid mass dampers using two types of electric servomotors: AC servomotors and linear-induction servomotors. Earthq. Eng. Struct. Dyn. 2001, 30, 1719-1743. [CrossRef]

36. Tan, P.; Liu, Y.; Zhou, F.; Teng, J. Hybrid mass dampers for Canton Tower. CTBUH J. 2012, 1, $24-29$.

37. Shen, Y.-J.; Wang, L.; Yang, S.-P.; Gao, G.-S. Nonlinear dynamical analysis and parameters optimization of four semi-active on-off dynamic vibration absorbers. J. Vib. Control 2011, 19, 143-160. [CrossRef] 
38. Hu, Y.; He, E. Active structural control of a floating wind turbine with a stroke-limited hybrid mass damper. J. Sound Vib. 2017, 410, 447-472. [CrossRef]

39. Bryson, A.E.; Ho, Y.C. Applied Optimal Control; Taylor \& Francis: New York, NY, USA, 1975.

40. Freeman, R.A.; Kokotovic, P.V. Robust Nonlinear Control Design: State-Space and Lyapunov Techniques; Birkhauser: Berlin/Heidelberg, Germany, 1996.

41. Itik, M. Optimal control of nonlinear systems with input constraints using linear time varying approximations. Nonlinear Anal. Model. Control 2016, 21, 400-412. [CrossRef]

42. Shukla, P.; Ghodki, D.; Manjarekar, N.S.; Singru, P.M. A Study of H infinity and H2 synthesis for Active Vibration Control. IFAC-PapersOnLine 2016, 49, 623-628. [CrossRef]

43. Villoslada, D.; Santos, M.; Tomás-Rodríguez, M. Identification and Validation of a Barge Floating Offshore Wind Turbine Model with Optimized Tuned Mass Damper. In Proceedings of the 10th EUROSIM Congress, Logroño, Spain, 1-5 July 2019.

44. Stewart, G.M.; Lackner, M.A. The effect of actuator dynamics on active structural control of offshore wind turbines. Eng. Struct. 2011, 33, 1807-1816. [CrossRef]

45. Sahu, G.N.; Singh, S.; Singh, A.; Law, M. Static and Dynamic Characterization and Control of a High-Performance ElectroHydraulic Actuator. Actuators 2020, 9, 46. [CrossRef]

46. Ioffe, A.D.; Tihomirov, V.M. Theory of Extremal Problems. Studies in Mathematics and Its Applications; North-Holland Publishing Company: Amsterdam, The Netherlands, 1979.

47. Lenhart, S.; Workman, J.T. Optimal Control Applied to Biological Models; CRC Press: New York, NY, USA, 2007.

48. Oates, W.S.; Smith, R.C. Nonlinear Optimal Control Techniques for Vibration Attenuation Using Magnetostrictive Actuators. J. Intell. Mater. Syst. Struct. 2008, 19, 193-209. [CrossRef]

49. Pinto, S.G.; Rodriguez, S.P.; Torcal, J.I.M. On the numerical solution of stiff IVPs by Lobatto IIIA Runge-Kutta methods. J. Comput. Appl. Math. 1997, 82, 129-148. [CrossRef]

50. Lord. Magneto-Rheological (MR) Technology. MR Controllable Friction Damper RD-1097-01 Product Bulletin. Printed in USA, 2005, Lord Corporation. Available online: www.lord.com (accessed on 20 August 2006).

51. Martynowicz, P.; Szydło, Z. Wind turbine's tower-nacelle model with magnetorheological tuned vibration absorber: The laboratory test rig. In Proceedings of the 14th International Carpathian Control Conference (ICCC), Rytro, Poland, 26-29 May 2013.

52. Martynowicz, P. Development of Laboratory Model of Wind Turbine's Tower-Nacelle System with Magnetorheological Tuned Vibration Absorber. Solid State Phenom. 2014, 208, 40-51. [CrossRef]

53. Snamina, J.; Martynowicz, P. Prediction of characteristics of wind turbine's tower-nacelle system from investigation of its scaled model. In Proceedings of the 6WCSCM: Sixth World Conference on Structural Control and Monitoring-Proceedings of the 6th edition of the World Conference of the International Association for Structural Control and Monitoring (IACSM), Barcelona, Spain, 15-17 July 2014. 